\title{
Studying the influence of nitrogen seeding in a detached-like hydrogen plasma by means of numerical simulations
}

\author{
R. Perillo ${ }^{1}$, R. Chandra ${ }^{1}$, G. R. A. Akkermans ${ }^{1}$, W. A. J. Vijvers ${ }^{1}$, W. A. A. D. Graef ${ }^{2}$, I. G. J. Classen ${ }^{1}$, J. van \\ Dijk $^{3}$, M. R. de Baar' ${ }^{1}$. \\ ${ }^{1}$ DIFFER - Dutch Institute for Fundamental Energy Research, De Zaale 20, 5612 AJ Eindhoven, the Netherlands \\ 2Plasma Matters B.V., Den Dolech 2, Flux 3.112, 5612 AZ Eindhoven, the Netherlands \\ ${ }^{3}$ Department of Applied Physics, EPG group, Eindhoven University of Technology, PO Box 513, 5600 MB Eindhoven, the Netherlands.
}

Keywords: MAR, Detachment, Linear plasma device, Impurity seeding, Nitrogen, Plasma chemistry, Recombination.

\begin{abstract}
The leading candidate for impurity seeding in ITER is currently nitrogen. To date, there are only a few studies on the plasma chemistry driven by $\mathrm{N}_{2} / \mathrm{H}_{2}$ seeding and its effect on the molecular-activated recombination of incoming atomic hydrogen ions in a detached-like scenario. Numerical simulations are needed to provide insights into such mechanisms. The numerous amount of plasma chemical reactions that may occur in such an environment cannot be entirely included in a 2 or 3 -dimensional code such as Eirene. A complete global plasma model, implemented with more than 100 plasma chemical equations and 20 species, has been set up on the basis of Plasimo code. This study shows two main nitrogen-included recombination reaction paths resulted to be dominant, i.e. the ion conversion of $\mathrm{NH}$ followed by dissociative recombination and a proton transfer between $\mathrm{H}_{2}{ }^{+}$and $\mathrm{N}_{2}$, producing $\mathrm{N}_{2} \mathrm{H}^{+}$. These two processes are referred to as N-MAR (nitrogen-molecular activated recombination) and have subsequently been implemented into Eunomia, a spatially-resolved Monte Carlo code, designed to simulate the neutrals inventory in linear plasma machines such as Pilot-PSI and MagnumPSI. To study the effect of $\mathrm{N}_{2}$ on the overall recombination, three cases of study have beenset up: from a defined puffing location with a constant total seeding rate of $\mathrm{H}_{2}+\mathrm{N}_{2}$, three $\mathrm{N}_{2}$ ratios have been simulated, i.e. 0,5 and $10 \%$. The parameter monitored is the density of atomic hydrogen, being the final hydrogenic product of any recombination mechanism in the scenario considered. The difference in $\mathrm{H}$ density between the $0 \%$ case and the $10 \%$ case is about a factor 3 . The importance of $\mathrm{NH}$ as electron donor is highlighted and N-MARs confirmed as reaction routes enhancing the conversion of ions to neutrals, making the heat loads to the divertor plate more tolerable. This work is a further step towards the full understanding of the role of $\mathrm{N}_{2}-\mathrm{H}_{2}$ molecules in a detached divertor plasma.
\end{abstract}

\section{Introduction}

Understanding and controlling plasma-surface interaction in the divertor region is one of the most important challenges towards realizing fusion power. Experiments have shown [1] [2] that impurity seeding facilitates the achievement of a so-called detached plasma regime. Nitrogen is currently the leading candidate for impurity seeding in ITER [3]. The divertor detached operational regime is characterized by a plasma pressure drop along magnetic field lines towards the target in the Scrape Off Layer (SOL) and a strong reduction of the plasma ion flux onto the target resulting in low power loads [4]. Such pressure drop is due to ion-neutral interactions which give rise to plasma momentum transfer to the walls through the neutral channel, ion removal by means of recombination mechanisms and plasma cooling due to radiation [5]. 
Molecular-Activated Recombination (referred to as MAR) and electron-ion recombination (EIR) are very efficient processes in Low $\mathrm{T}(\leq 1.5 \mathrm{eV})[6]$ and involve molecular hydrogen in vibrational excited states[7]. The rate coefficients for these processes are highlighted in figure 1. The first experimental investigations of MAR have been carried out in linear machines Nagdis-II [8] and ULS[9].

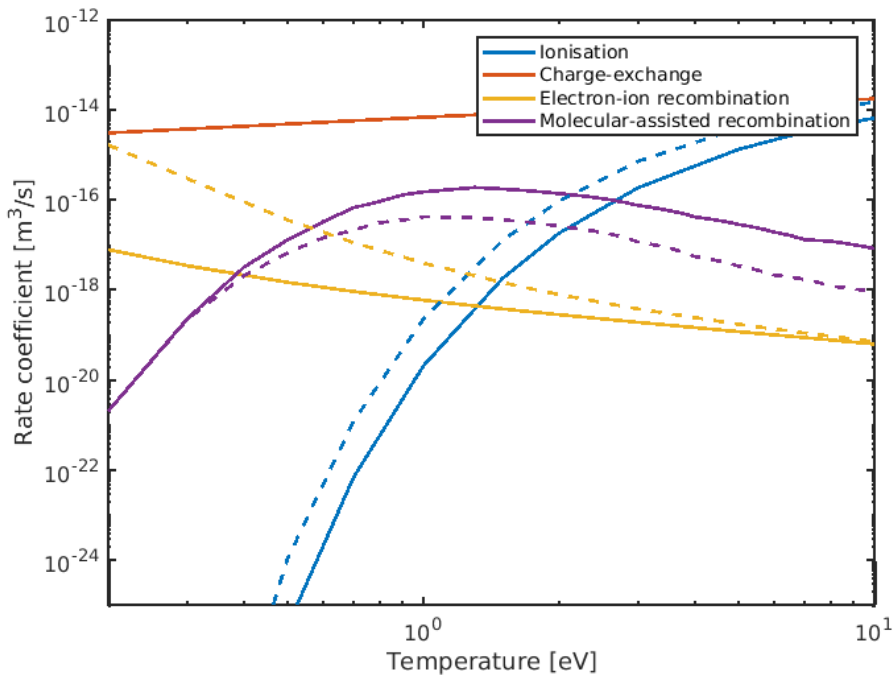

Figure 1. Rate coefficients of the most relevant hydrogenic processes in divertor plasmas as a function of $T_{e}$. Straight and dotted lines correspond to $n_{e}=10^{21}$ and $10^{19} \mathrm{~m}^{-3}$ respectively.
The aim of this work is to investigate the plasma chemistry induced by nitrogen in a detached-like hydrogen plasma, pointing out the most important processes to be added in spatially-resolved codes, where an implementation of the whole plasma chemistry would not be computationally feasible. Little is known on the detailed plasma chemical processes occurring in ITER divertor relevant conditions i.e. high density, low temperature plasmas in the presence of nitrogen. To study this complex scenario, an extensive global plasma model of $\mathrm{H}_{2}+\mathrm{N}_{2}$ chemistry has been set up on the basis of Plasimo code[10]. The general features of the global model are presented in section 2.1, while the plasma chemistry is described in sections 2.1.2 and 2.1.3. The model is created with the purpose of identifying the dominant plasma-chemical processes occurring in the plasma close to the target when $\mathrm{N}_{2}$ is added into the system. In order to prove the reliability of the reduced set of chemical equations, a reduced global model has been implemented and the outputs are compared with the full version for three different plasma scenarios. The results are in good agreement in all cases and are shown in section 2.2.6. The reduced set of chemical equations relevant for Magnum-PSI i.e. highdensity low-temperature plasma has been subsequently implemented in Eunomia [11], a spatially resolved Monte-Carlo code for the transport of neutrals originally developed for the Magnum-PSI[12] predecessor Pilot-PSI[13]. To study the influence of $\mathrm{N}_{2}$ and related species on the recombination mechanisms, the density of atomic hydrogen has been traced for three different seeding cases. Conversion of ions to neutrals has been proved to be enhanced by the presence of nitrogen by up to $30 \%$. The output are shown is section 3.3. Finally, a summary of this work, together with the conclusions, are given in section 4.

\section{Global modelling with Plasimo code}

In Global Models spatial averages of the physical parameters are calculated from plasma ignition to the fulfilment of the steady state[14]. The outcomes of the zero-dimensional simulation is collected by solving a system of coupled differential equations i.e. the energy balance, the quasi - neutrality condition and the particle balance, whose solution describes the evolution of ionic and neutral species as a function of time. The electron energy balance is solved simultaneously. The power is assumed to be uniformly distributed and the plasma is spatially homogeneous throughout the wholevolume. The input parameters to be defined are input power and density of precursor gases $\left(H_{2}\right.$ and $\left.N_{2}\right)$, while $n_{e}$ and $T_{e}$ are given as output of the simulation.

The source terms are formulated from the reaction rates, thus every reaction can be initiated by any of the species included in the model. This type of code is computationally less expensive than spatially 
resolved hybrid models, hence we are able to include a detailed and exstensive chemistry, without causing any significant increasing of the computational effort [15].

In the model, the electron energy distribution function (EEDF) is assumed to be maxwellian.

Despite the limitations imposed by a zero-dimensional simulation, where no transport effects are considered, important outputs can be obtained providing detailed insights into the dominant atomic and molecular-induced processes governing the volume collisions in a detached-like plasma system.

\subsection{Governing equations}

The time-dependent evaluation of number densities of the chemical species is calculated as follows:

$$
\frac{d n_{i}}{d t}=\sum_{r}\left(v_{i}^{p}-v_{i}^{d}\right) k_{r}(t) \prod n_{i}^{v_{d}}=S_{i}
$$

where $v_{i}^{p}$ and $v_{i}^{d}$ are the stoichiometric coefficients of the reactants $(d)$ and the products $(p)$ of the reaction, $k_{r}(t)$ is the rate coefficient and $n_{i}$ is the density of species $i$.

The electron energy balance is defined as:

$$
\frac{d\left(\frac{3}{2} n_{e} e T_{e}\right)}{d t}=P_{\text {input }}(t)-Q_{\text {inelas }}-Q_{\text {elas }}
$$

where $n_{e}$ and $T_{e}$ are the electron density $\left[\mathrm{m}^{-3}\right]$ and temperature [eV] respectively, $e$ the elementary charge, $P_{\text {input }}$ the input power density, $Q_{\text {inelas }}$ and $Q_{\text {elas }}$ the energy losses from inelastic and elastic collisions between electrons and heavy particles.

In inelastic electron-induced collisions with heavy particles, the energy difference between left and right hand side of the reaction is due to energy loss by the electron. Hence, the total inelastic source term is written as:

$$
Q_{\text {inelas }}=\sum_{r} E_{e} n_{r} n_{e} k_{\text {reac }}=E_{e} R
$$

With $E_{e}$ the electron energy transfer (one per reaction) and $R$ the triple product of rate times reactants densities.

In this model quasi-neutrality is assumed, thus plasma is neutrally charged. The electron density is therefore calculated from:

$$
n_{e}=\sum_{r} \frac{n_{i} q_{i}}{e}
$$

Where $n_{i}$ is the density of the ionic species $i, q_{i}$ its charge and $e$ the elementary charge.

The totality of the power supplied to the gas is assumed to be consumed by the plasma, thus lost and supplied power must balance. The input power density is then used to create ion - electron pairs by means of inelastic electron - induced processes.

\subsubsection{Chemical model}

The chemical species simulated in this study are reported in Table 1. The energy of electrons in our case of study is generally not high enough to cause direct dissociation of $\mathrm{N}_{2}\left(E_{a}=9.79 \mathrm{eV}\right)$. It has been recently reported [16] that the $A^{3} \sum$ excited molecule can act as intermediate compound for the dissociation of $\mathrm{N}_{2}$ in low T plasma predominantly via the reaction $\mathrm{N}_{2}{ }^{*}\left(A^{3} \sum\right)+\mathrm{H} \rightarrow \mathrm{NH}+\mathrm{N}$ and to a minor extent $(\approx 30 \%)$ via $\mathrm{N}_{2}{ }^{*}\left(A^{3} \sum\right)+e \rightarrow N+N$. These processes, together with ionization of $\mathrm{N}_{2}$ from the $A^{3} \sum$ state, have been included. Diazenilium ions $\mathrm{N}_{2} \mathrm{H}^{+}$and ammonium $\mathrm{NH}_{4}{ }^{+}$are included in the 
simulations. An extensive set including all the $\mathrm{NH}_{\mathrm{x}}$ and $\mathrm{NH}_{\mathrm{x}}{ }^{+}$has been implemented in the code. Although it is now well-establ ished that the hydrogenation of $\mathrm{N}$ to produce ammonia occurs mainly on the surface [21], these species have been added due to the role they play in the volume phase such as ion conversion, proton transfer and recombination processes. It's worth stressing that the aim is to obtain a reduced set of chemical equations and that global modelling allows us to study a large number of different processes among several species. Molecular hydrogen in vibrational excited state $(v=4)$ has been added in the model, given the important role it plays in the ion conversion with $\mathrm{H}^{+}$, which is the main ion species in our plasma.

A recent work carried out by Body et al. [17] and published in this journal provides a detailed description of plasma-chemical processes leading to the production of ammonia. Particular efforts are thereby spent in the modelling of plasma-wall heterogeneous reactions, given the importance they have in the synthesis of $\mathrm{NH}_{3}$. In the present work, the selection of processes has been done focusing on volume processes relevant in detached-like hydrogen plasma in the presence of nitrogen, in order to evaluate the role of $\mathrm{N}$ and $\mathrm{N}_{\mathrm{x}}-\mathrm{H}_{\mathrm{y}}$ species in recombination mechanisms. The list of the plasmachemical reactions adopted in this study is presented in Table 2 in section 2.1.3.

\begin{tabular}{|c|c|c|}
\hline $\mathrm{H}_{2}$ species & $\mathrm{N}_{2}$ species & $\mathrm{H}_{2}-\mathrm{N}_{2}$ species \\
\hline $\mathrm{H}, \mathrm{H}_{2}, \mathrm{H}^{+}, \mathrm{H}_{2}^{+}, \mathrm{H}_{2} v_{n=4}, \mathrm{H}_{3}^{+}$ & $N_{2}, \mathrm{~N}, \mathrm{~N}_{2}^{*}\left(\mathrm{~A}^{3} \Sigma\right), \mathrm{N}_{2}^{+}, \mathrm{N}^{+}$ & $\mathrm{NH}, \mathrm{NH}_{2}, \mathrm{NH}_{3}, \mathrm{NH}_{3}^{+}, \mathrm{NH}_{2}^{+}, \mathrm{NH}^{+}, \mathrm{N}_{2} \mathrm{H}^{+}, \mathrm{NH}_{4}^{+}$ \\
\hline
\end{tabular}

Table 1. the chemical species included.

\subsubsection{Plasma chemical reactions}

The chemical equations incorporated in the model cover a wide range of process types, i.e. ionization, dissociation, dissociative ionization, dissociative recombination, ion-neutral, neutral-neutral and elastic collisions. The set of the chemical equations adopted in this work is listed in table 2 . The rate coefficient for ionization and elastic coll isions with electrons is gained by averaging the product of cross section and velocity over the EEDF. The relation can be written explicitily[15]:

$$
k_{i}=\int_{E_{t h}}^{\infty} \sigma_{i}(E) v(E) f(E) d E
$$

With $E_{t h}$ the threshold energy of the collision, $E$ the electron energy, $f(E)$ the electron energy distributionfunction, $v(E)$ the electron velocity and $\sigma_{i}$ the cross section of collision $i$. Data concerning the remaining classes of reactions have been taken from the most comprehensive databases available in the literature such as UMIST, LxCat, NIST, Anichich's review and are referenced in table 2. These rates are expressed in the generalized Arrhenius form[18]:

$$
k\left(T_{e}\right)=A *\left(\frac{T_{e}}{1 e V}\right)^{n} * \exp \left(-\frac{E_{a}}{T_{e}}\right)
$$

Where $A$ is declared in $\mathrm{cm}^{3} \mathrm{~s}^{-1}$ and $E_{a}$, the activation energy of the reaction, together with $T_{e}$, in $\mathrm{eV}$. The temperature of neutrals in the simulations $\left(T_{g}\right)$ has been set at $0.2 \mathrm{eV}$. Such value has been estimated by numerical simulations in [19] ) to be in the temperature range of molecules in the PilotPSI hydrogen plasma beam, which is characterized by very similar plasma parameters to MagnumPSI's, in terms of electron density and temperature.

\begin{tabular}{|c|c|c|c|}
\hline N\#. & Reaction & Rate coefficient $\left(\mathrm{cm}^{3} \mathrm{~s}^{-1}\right)$ & Reference \\
\hline 1 & $H+e^{-} \rightarrow H^{+}+2 e^{-}$ & from cross section & {$[20]$} \\
\hline 2 & $H_{2}+e^{-} \rightarrow H_{2}^{+}+2 e^{-}$ & from cross section & {$[20]$} \\
\hline 3 & $N+e^{-} \rightarrow N^{+}+2 e^{-}$ & from cross section & {$[21]$} \\
\hline 4 & $N_{2}+e^{-} \rightarrow N_{2}^{+}+2 e^{-}$ & from cross section & {$[21]$} \\
\hline 5 & $N_{2}+e^{-} \rightarrow N_{2}^{*}\left(A^{3} \Sigma\right)+e^{-}$ & from cross section & {$[22]$} \\
\hline 6 & $N_{2}^{*}\left(A^{3} \Sigma\right)+e^{-} \rightarrow N_{2}^{+}+2 e^{-}$ & from cross section & {$[23]$} \\
\hline
\end{tabular}




\begin{tabular}{|c|c|c|c|}
\hline 7 & $N_{2}+e^{-} \rightarrow N^{+}+N+2 e^{-}$ & $2.9 \times 10^{-9} \times T_{e}^{0.72} \times \exp \left(-29.71 / T_{e}\right)$ & [24] \\
\hline 8 & $H_{2}+e^{-} \rightarrow H^{+}+H+2 e^{-}$ & $9.4 \times 10^{-10} \times T_{e}^{0.45} \times \exp \left(-29.94 / T_{e}\right)$ & [25] \\
\hline 9 & $H_{2}+e^{-} \rightarrow H_{2} v_{n=4}+e^{-}$ & $6.7 \times 10^{-10} \times T_{e}^{1.82} \times \exp \left(-1.89 / T_{e}\right)$ & [26] \\
\hline 10 & $N H+e^{-} \rightarrow N H^{+}+2 e^{-}$ & $2.1 \times 10^{-8} \times T_{e}^{0.37} \times \exp \left(-15.49 / T_{e}\right)$ & [27] \\
\hline 11 & $N H+e^{-} \rightarrow N^{+}+H+2 e^{-}$ & $7.6 \times 10^{-9} \times T_{e}^{0.29} \times \exp \left(-16.82 / T_{e}\right)$ & [27] \\
\hline 12 & $\mathrm{NH}_{2}+e^{-} \rightarrow \mathrm{NH}_{2}^{+}+2 e^{-}$ & $1.3 \times 10^{-8} \times T_{e}^{0.5} \times \exp \left(-12.4 / T_{e}\right)$ & [27] \\
\hline 13 & $\mathrm{NH}_{2}+e^{-} \rightarrow \mathrm{NH}^{+}+\mathrm{H}+2 e^{-}$ & $2.2 \times 10^{-8} \times T_{e}^{0.21} \times \exp \left(-17.97 / T_{e}\right)$ & {$[27]$} \\
\hline 14 & $\mathrm{NH}_{3}+e^{-} \rightarrow \mathrm{NH}_{3}^{+}+2 e^{-}$ & $1.5 \times 10^{-8} \times T_{e}^{0.4} \times \exp \left(-13.61 / T_{e}\right)$ & {$[27]$} \\
\hline 15 & $\mathrm{NH}_{3}+e^{-} \rightarrow \mathrm{NH}_{2}^{+}+\mathrm{H}+2 e^{-}$ & $1.6 \times 10^{-8} * T_{e}^{0.34} \times \exp \left(-15.41 / T_{e}\right)$ & [27] \\
\hline 16 & $\mathrm{NH}_{3}+e^{-} \rightarrow \mathrm{NH}^{+}+\mathrm{H}+\mathrm{H}+2 e^{-}$ & $5.4 \times 10^{-10} \times T_{e}^{0.37} \times \exp \left(-26.06 / T_{e}\right)$ & [27] \\
\hline 17 & $\mathrm{NH}_{3}+e^{-} \rightarrow \mathrm{N}^{+}+\mathrm{H}+\mathrm{H}_{2}+2 e^{-}$ & $8.8 \times 10^{-11} \times T_{e}^{0.59} \times \exp \left(-29 / T_{e}\right)$ & [28] \\
\hline 18 & $\mathrm{NH}_{3}+e^{-} \rightarrow \mathrm{H}^{+}+\mathrm{NH}_{2}+2 e^{-}$ & $1.3 \times 10^{-10} \times T_{e}^{0.47} \times \exp \left(-28.55 / T_{e}\right)$ & {$[28]$} \\
\hline 19 & $H_{2}^{+}+e^{-} \rightarrow H+H$ & $1.6 \times 10^{-8} \times\left(T_{e} / 0.026\right)^{-0.43}$ & [29] \\
\hline 20 & $H_{3}^{+}+e^{-} \rightarrow H_{2}+H$ & $2.34 \times 10^{-8} \times\left(T_{e} / 0.026\right)^{-0.52}$ & [30] \\
\hline 21 & $H_{3}^{+}+e^{-} \rightarrow H+H+H$ & $4.36 \times 10^{-8} \times\left(T_{e} / 0.026\right)^{-0.52}$ & {$[30]$} \\
\hline 22 & $N_{2}^{+}+e^{-} \rightarrow N+N$ & $1.7 \times 10^{-7} \times\left(T_{e} / 0.026\right)^{-0.3}$ & [31] \\
\hline 23 & $N H^{+}+e^{-} \rightarrow N+H$ & $4.3 \times 10^{-8} \times\left(T_{e} / 0.026\right)^{-0.5}$ & [29] \\
\hline 24 & $\mathrm{NH}_{2}^{+}+e^{-} \rightarrow \mathrm{NH}+\mathrm{H}$ & $1.02 \times 10^{-7} \times\left(T_{e} / 0.026\right)^{-0.4}$ & [32] \\
\hline 25 & $\mathrm{NH}_{2}^{+}+e^{-} \rightarrow \mathrm{N}+\mathrm{H}_{2}$ & $1.98 \times 10^{-8} \times\left(T_{e} / 0.026\right)^{-0.4}$ & [32] \\
\hline 26 & $\mathrm{NH}_{3}^{+}+e^{-} \rightarrow \mathrm{NH}+2 \mathrm{H}$ & $1.55 \times 10^{-7} \times\left(T_{e} / 0.026\right)^{-0.5}$ & [29] \\
\hline 27 & $\mathrm{NH}_{3}^{+}+e^{-} \rightarrow \mathrm{NH}_{2}+\mathrm{H}$ & $1.55 \times 10^{-1} \times\left(T_{e} / 0.026\right)^{-0.5}$ & [29] \\
\hline 28 & $\mathrm{NH}_{4}^{+}+\mathrm{e}^{-} \rightarrow \mathrm{NH}_{3}+\mathrm{H}$ & $8.49 \times 10^{-7} \times\left(T_{e} / 0.026\right)^{-0.6}$ & [32] \\
\hline 29 & $\mathrm{NH}_{4}^{+}+\mathrm{e}^{-} \rightarrow \mathrm{NH}_{2}+2 \mathrm{H}$ & $3.77 \times 10^{-8} \times\left(T_{e} / 0.026\right)^{-0.6}$ & [32] \\
\hline 30 & $\mathrm{~N}_{2} \mathrm{H}^{+}+e^{-} \rightarrow \mathrm{N}_{2}+\mathrm{H}$ & $5.13 \times 10^{-8} \times\left(T_{e} / 0.026\right)^{-0.72}$ & [33] \\
\hline 31 & $\mathrm{~N}_{2} \mathrm{H}^{+}+\mathrm{e}^{-} \rightarrow \mathrm{NH}+\mathrm{N}$ & $2.09 \times 10^{-8} \times\left(T_{e} / 0.026\right)^{-0.72}$ & [34] \\
\hline 32 & $N_{2}+e^{-} \rightarrow N+N+e^{-}$ & $2.4 \times 10^{-8} \times T_{e}^{0.27} \times \exp \left(-15.53 / T_{e}\right)$ & [24] \\
\hline 33 & $H_{2}+e^{-} \rightarrow H+H+e^{-}$ & $8.4 \times 10^{-8} \times T_{e}^{-0.45} \times \exp \left(-11.18 / T_{e}\right)$ & [25] \\
\hline 34 & $N H+e^{-} \rightarrow N+H+e^{-}$ & $4.7 \times 10^{-8} \times T_{e}^{-0.22} \times \exp \left(-7.69 / T_{e}\right)$ & [35] \\
\hline 35 & $\mathrm{NH}_{2}+e^{-} \rightarrow \mathrm{NH}+\mathrm{H}+e^{-}$ & $4.5 \times 10^{-8} \times T_{e}^{-0.22} \times \exp \left(-7.61 / T_{e}\right)$ & [35] \\
\hline 36 & $\mathrm{NH}_{2}+e^{-} \rightarrow \mathrm{N}+\mathrm{H}_{2}+e^{-}$ & $1.5 \times 10^{-8} \times T_{e}^{0.38} \times \exp \left(-11.44 / T_{e}\right)$ & [35] \\
\hline 37 & $\mathrm{NH}_{3}+e^{-} \rightarrow \mathrm{NH}+\mathrm{H}+\mathrm{H}+e^{-}$ & $1.3 \times 10^{-8} \times T_{e}^{0.38} \times \exp \left(-11.06 / T_{e}\right)$ & [36] \\
\hline 38 & $\mathrm{NH}_{3}+e^{-} \rightarrow \mathrm{NH}_{2}+\mathrm{H}+e^{-}$ & $4.2 \times 10^{-8} \times T_{e}^{-0.19} \times \exp \left(-7.59 / T_{e}\right)$ & [36] \\
\hline 39 & $\mathrm{NH}_{3}+e^{-} \rightarrow \mathrm{NH}+\mathrm{H}_{2}+e^{-}$ & $4.1 \times 10^{-8} \times T_{e}^{-0.26} \times \exp \left(-4.81 / T_{e}\right)$ & [36] \\
\hline 40 & $\mathrm{H}_{2}+\mathrm{NH} \rightarrow \mathrm{NH}_{2}+\mathrm{H}$ & $5.96 \times 10^{-11} \times \exp \left(-0.67 / T_{g}\right)$ & [37] \\
\hline 41 & $\mathrm{NH}_{3}+\mathrm{H} \rightarrow \mathrm{NH}_{2}+\mathrm{H}_{2}$ & $8.4 \times 10^{-14} \times\left(T_{g} / 0.026\right)^{4.1} \times \exp \left(-0.41 / T_{g}\right)$ & [38] \\
\hline 42 & $\mathrm{NH}+\mathrm{NH}_{2} \rightarrow \mathrm{NH}_{3}+\mathrm{N}$ & $1.66 \times 10^{-12}$ & [38] \\
\hline 43 & $\mathrm{~N}+\mathrm{NH}_{2} \rightarrow \mathrm{N}_{2}+\mathrm{H}_{2}$ & $1.2 \times 10^{-10}$ & [39] \\
\hline 44 & $\mathrm{NH}_{2}+\mathrm{H}_{2} \rightarrow \mathrm{NH}_{3}+\mathrm{H}$ & $5.4 \times 10^{-11} \times \exp \left(-0.56 / T_{g}\right)$ & {$[40]$} \\
\hline 45 & $\mathrm{NH}+\mathrm{NH} \rightarrow \mathrm{NH}_{2}+\mathrm{N}$ & $1.7 \times 10^{-12} \times\left(T_{g} / 0.026\right)^{1.5}$ & [41] \\
\hline 46 & $\mathrm{NH}+\mathrm{NH} \rightarrow \mathrm{N}_{2}+\mathrm{H}+\mathrm{H}$ & $8.5 \times 10^{-11}$ & [18] \\
\hline 47 & $\mathrm{NH}_{2}+\mathrm{H} \rightarrow \mathrm{NH}+\mathrm{H}_{2}$ & $6.6 \times 10^{-11} \times \exp \left(-0.1586 / T_{g}\right)$ & {$[42]$} \\
\hline 48 & $\mathrm{NH}+\mathrm{NH} \rightarrow \mathrm{N}_{2}+\mathrm{H}_{2}$ & $5 \times 10^{-14} \times\left(T_{g} / 0.026\right)$ & {$[42]$} \\
\hline 49 & $\mathrm{H}_{2}+\mathrm{N} \rightarrow \mathrm{NH}+\mathrm{H}$ & $4.65 \times 10^{-11} \times \exp \left(-1.43 / T_{g}\right)$ & [37] \\
\hline 50 & $\mathrm{~N}+\mathrm{NH} \rightarrow \mathrm{N}_{2}+\mathrm{H}$ & $5 \times 10^{-11}$ & [39] \\
\hline 51 & $\mathrm{NH}+\mathrm{H} \rightarrow \mathrm{N}+\mathrm{H}_{2}$ & $5.4 \times 10^{-11} \times \exp \left(-0.0142 / T_{g}\right)$ & {$[42]$} \\
\hline 52 & $\mathrm{~N}^{+}+\mathrm{H}_{2} \rightarrow \mathrm{NH}^{+}+\mathrm{H}$ & $5 \times 10^{-10}$ & {$[43]$} \\
\hline 53 & $\mathrm{~N}^{+}+\mathrm{NH}_{2} \rightarrow \mathrm{NH}_{2}^{+}+\mathrm{N}$ & $1 \times 10^{-9}$ & [44] \\
\hline 54 & $N^{+}+H \rightarrow H^{+}+N$ & $2 \times 10^{-10}$ & [45] \\
\hline 55 & $N^{+}+N_{2} \rightarrow N+N_{2}^{+}$ & $2 \times 10^{-11}$ & {$[43]$} \\
\hline 56 & $N^{+}+N H \rightarrow N H^{+}+N$ & $3.7 \times 10^{-10} \times\left(T_{q} / 0.026\right)^{-0.5}$ & [44] \\
\hline 57 & $\mathrm{~N}^{+}+\mathrm{NH}_{3} \rightarrow \mathrm{N}_{2} \mathrm{H}^{+}+\mathrm{H}_{2}$ & $2.1 \times 10^{-10}$ & {$[43]$} \\
\hline 58 & $N^{+}+N H \rightarrow N_{2}^{+}+H$ & $3.7 \times 10^{-10} \times\left(T_{g} / 0.026\right)^{-0.5}$ & {$[44]$} \\
\hline 59 & $N^{+}+N_{3} \rightarrow N_{3}^{+}+N$ & $1.7 \times 10^{-9}$ & [43] \\
\hline 60 & $\mathrm{~N}^{+}+\mathrm{NH}_{3} \rightarrow \mathrm{NH}_{2}^{+}+\mathrm{NH}$ & $4.7 \times 10^{-10}$ & [43] \\
\hline 61 & $\mathrm{H}^{+}+\mathrm{NH}_{3} \rightarrow \mathrm{NH}_{3}^{+}+\mathrm{H}$ & $3.7 \times 10^{-9} \times\left(T_{g} / 0.026\right)^{-0.5}$ & {$[46]$} \\
\hline 62 & $H^{+}+N H \rightarrow N H^{+}+H$ & $2.1 \times 10^{-9} \times\left(T_{g} / 0.026\right)^{-0.5}$ & [44] \\
\hline 63 & $\mathrm{H}^{+}+\mathrm{NH}_{2} \rightarrow \mathrm{NH}_{2}^{+}+\mathrm{H}$ & $2.9 \times 10^{-9} \times\left(T_{g} / 0.026\right)^{-0.5}$ & {$[44]$} \\
\hline 64 & $H^{+}+H_{2} v_{n=4} \rightarrow H+H_{2}^{+}$ & $2.5 \times 10^{-9}$ & {$[47]$} \\
\hline
\end{tabular}




\begin{tabular}{|c|c|c|c|}
\hline 65 & $\mathrm{H}_{2}^{+}+\mathrm{NH}_{3} \rightarrow \mathrm{H}_{2}+\mathrm{NH}_{3}^{+}$ & $5.7 \times 10^{-9}$ & {$[43]$} \\
\hline 66 & $\mathrm{H}_{2}^{+}+\mathrm{N}_{2} \rightarrow \mathrm{N}_{2} \mathrm{H}^{+}+\mathrm{H}$ & $2 \times 10^{-9}$ & {$[43]$} \\
\hline 67 & $\mathrm{H}_{2}^{+}+\mathrm{N} \rightarrow \mathrm{NH}^{+}+\mathrm{H}$ & $1.9 \times 10^{-9}$ & {$[44]$} \\
\hline 68 & $H_{2}^{+}+N \rightarrow N^{+}+H_{2}$ & $5 \times 10^{-10}$ & {$[44]$} \\
\hline 69 & $\mathrm{H}_{2}^{+}+\mathrm{NH} \rightarrow \mathrm{NH}^{+}+\mathrm{H}_{2}$ & $7.6 \times 10^{-10} \times\left(T_{g} / 0.026\right)^{-0.5}$ & {$[43]$} \\
\hline 70 & $\mathrm{H}_{2}^{+}+\mathrm{NH}_{2} \rightarrow \mathrm{NH}_{2}^{+}+\mathrm{H}_{2}$ & $7.6 \times 10^{-10} \times\left(T_{g} / 0.026\right)^{-0.5}$ & {$[44]$} \\
\hline 71 & $\mathrm{H}_{2}^{+}+\mathrm{NH} \rightarrow \mathrm{NH}_{2}^{+}+\mathrm{H}$ & $2.1 \times 10^{-9} \times\left(T_{a} / 0.026\right)^{-0.5}$ & {$[44]$} \\
\hline 72 & $\mathrm{H}_{2}^{+}+\mathrm{NH}_{2} \rightarrow \mathrm{NH}_{3}^{+}+\mathrm{H}$ & $5 \times 10^{-11}$ & {$[45]$} \\
\hline 73 & $\mathrm{H}_{2}^{+}+\mathrm{NH}_{3} \rightarrow \mathrm{NH}_{4}^{+}+\mathrm{H}$ & $5 \times 10^{-11}$ & {$[45]$} \\
\hline 74 & $\mathrm{H}_{2}^{+}+\mathrm{H}_{2} \rightarrow \mathrm{H}_{3}^{+}+\mathrm{H}$ & $2 \times 10^{-9}$ & {$[15]$} \\
\hline 75 & $\mathrm{H}_{3}^{+}+\mathrm{N} \rightarrow \mathrm{NH}^{+}+\mathrm{H}_{2}$ & $2.6 \times 10^{-10}$ & {$[15]$} \\
\hline 76 & $\mathrm{H}_{3}^{+}+\mathrm{N} \rightarrow \mathrm{NH}_{2}^{+}+\mathrm{H}$ & $3.9 \times 10^{-10}$ & {$[15]$} \\
\hline 77 & $\mathrm{H}_{3}^{+}+\mathrm{NH}_{3} \rightarrow \mathrm{NH}_{4}^{+}+\mathrm{H}_{2}$ & $4.4 \times 10^{-9} \times\left(T_{g} / 0.026\right)^{-0.5}$ & {$[15]$} \\
\hline 78 & $\mathrm{H}_{3}^{+}+\mathrm{NH}_{2} \rightarrow \mathrm{NH}_{3}^{+}+\mathrm{H}_{2}$ & $1.8 \times 10^{-9} \times\left(T_{g} / 0.026\right)^{-0.5}$ & {$[44]$} \\
\hline 79 & $\mathrm{H}_{3}^{+}+\mathrm{NH} \rightarrow \mathrm{NH}_{2}^{+}+\mathrm{H}_{2}$ & $1.3 \times 10^{-9} \times\left(T_{g} / 0.026\right)^{-0.5}$ & {$[44]$} \\
\hline 80 & $\mathrm{H}_{3}^{+}+\mathrm{N}_{2} \rightarrow \mathrm{N}_{2} \mathrm{H}^{+}+\mathrm{H}_{2}$ & $1.9 \times 10^{-9}$ & {$[15]$} \\
\hline 81 & $N_{2}^{*}\left(A^{3} \Sigma\right)+H \rightarrow N H+N$ & $2.8 \times 10^{-10}$ & {$[16]$} \\
\hline 82 & $\mathrm{NH}^{+}+\mathrm{H}_{2} \rightarrow \mathrm{NH}_{2}^{+}+\mathrm{H}$ & $1 \times 10^{-9}$ & {$[16]$} \\
\hline 83 & $\mathrm{NH}^{+}+\mathrm{N} \rightarrow \mathrm{N}_{2}^{+}+\mathrm{H}$ & $1.3 \times 10^{-9}$ & {$[44]$} \\
\hline 84 & $\mathrm{NH}^{+}+\mathrm{N}_{2} \rightarrow \mathrm{N}_{2} \mathrm{H}^{+}+\mathrm{N}$ & $6.5 \times 10^{-10}$ & {$[43]$} \\
\hline 85 & $\mathrm{NH}^{+}+\mathrm{NH} \rightarrow \mathrm{NH}_{2}^{+}+\mathrm{N}$ & $1 \times 10^{-9}$ & {$[44]$} \\
\hline 86 & $\mathrm{NH}^{+}+\mathrm{NH}_{2} \rightarrow \mathrm{NH}_{3}^{+}+\mathrm{N}$ & $1.5 \times 10^{-9}$ & {$[44]$} \\
\hline 87 & $\mathrm{NH}^{+}+\mathrm{NH}_{2} \rightarrow \mathrm{NH}_{2}^{+}+\mathrm{NH}$ & $1.8 \times 10^{-9}$ & {$[45]$} \\
\hline 88 & $\mathrm{NH}^{+}+\mathrm{NH}_{3} \rightarrow \mathrm{NH}+\mathrm{NH}_{3}^{+}$ & $1.8 \times 10^{-9}$ & {$[45]$} \\
\hline 89 & $\mathrm{NH}^{+}+\mathrm{NH}_{3} \rightarrow \mathrm{NH}_{4}^{+}+\mathrm{N}$ & $6 \times 10^{-10}$ & {$[43]$} \\
\hline 90 & $\mathrm{NH}_{2}^{+}+\mathrm{N} \rightarrow \mathrm{N}_{2} \mathrm{H}^{+}+\mathrm{N}$ & $9.1 \times 10^{-11}$ & {$[44]$} \\
\hline 91 & $\mathrm{NH}_{2}^{+}+\mathrm{NH} \rightarrow \mathrm{NH}_{3}^{+}+\mathrm{N}$ & $7.3 \times 10^{-10}$ & {$[44]$} \\
\hline 92 & $\mathrm{NH}_{2}^{+}+\mathrm{NH}_{3} \rightarrow \mathrm{NH}_{4}^{++}+\mathrm{NH}$ & $1.2 \times 10^{-9}$ & {$[43]$} \\
\hline 93 & $\mathrm{NH}_{2}^{+}+\mathrm{NH}_{3} \rightarrow \mathrm{NH}_{2}+\mathrm{NH}_{3}^{+}$ & $1.2 \times 10^{-9}$ & {$[43]$} \\
\hline 94 & $\mathrm{NH}_{2}^{+}+\mathrm{H}_{2} \rightarrow \mathrm{NH}_{3}^{+}+\mathrm{H}$ & $2 \times 10^{-10}$ & {$[43]$} \\
\hline 95 & $\mathrm{NH}_{3}^{+}+\mathrm{NH}_{3} \rightarrow \mathrm{NH}_{4}^{+}+\mathrm{NH}_{2}$ & $2.1 \times 10^{-9}$ & {$[43]$} \\
\hline 96 & $\mathrm{NH}_{3}^{+}+\mathrm{NH} \rightarrow \mathrm{NH}_{4}^{+}+\mathrm{N}$ & $7.1 \times 10^{-10} \times\left(T_{g} / 0.026\right)^{-0.5}$ & {$[44]$} \\
\hline 97 & $\mathrm{NH}_{3}^{+}+\mathrm{H}_{2} \rightarrow \mathrm{NH}_{4}^{+}+\mathrm{H}$ & $4.4 \times 10^{-13}$ & {$[43]$} \\
\hline 98 & $\mathrm{~N}_{2} \mathrm{H}^{+}+\mathrm{NH}_{3} \rightarrow \mathrm{NH}_{4}^{+}+\mathrm{N}_{2}$ & $2.3 \times 10^{-9}$ & {$[43]$} \\
\hline 99 & $\mathrm{~N}_{2}^{+}+\mathrm{H}_{2} \rightarrow \mathrm{NH}_{2}^{+}+\mathrm{H}$ & $2 \times 10^{-9}$ & {$[43]$} \\
\hline 100 & $\mathrm{~N}_{2}^{+}+\mathrm{NH}_{3} \rightarrow \mathrm{N}_{2}+\mathrm{NH}_{3}^{+}$ & $2 \times 10^{-9}$ & {$[43]$} \\
\hline 101 & $N_{2}^{+}+N \rightarrow N_{2}+N^{+}$ & $1 \times 10^{-11}$ & [43] \\
\hline 102 & $H_{2}+e^{-} \rightarrow H_{2}+e^{-}$ & from cross section & {$[48]$} \\
\hline 103 & $H+e^{-} \rightarrow H+e^{-}$ & from cross section & {$[20]$} \\
\hline 104 & $N_{2}+e^{-} \rightarrow N_{2}+e^{-}$ & from cross section & {$[24]$} \\
\hline 105 & $N+e^{-} \rightarrow N+e^{-}$ & from cross section & {$[21]$} \\
\hline 106 & $\mathrm{NH}_{3}+e^{-} \rightarrow \mathrm{NH}_{3}+e^{-}$ & from cross section & {$[23]$} \\
\hline
\end{tabular}

Table 2. Reactions included in the global model.

\subsection{Global model results}

Hydrogen plasmas with nitrogen content have been widely studied in the last few decades [49],[50], [51]. The aim of such studies mostly concerned the role of plasma in lowering the activation energy needed for the catalytic synthesis of ammonia. The parameters of those plasmas were substantially different from the scenario considered in this paper, i.e. far from the high-density low-temperature plasmas produced in linear machines and divertors. The purpose of this study is to characterize the plasma chemistry relevant for $\mathrm{N}_{2}$-seeded divertor hydrogen plasma. In particular, we are interested in investigating the recombination mechanisms of $\mathrm{H}^{+}$introduced by the presence of nitrogen in the volume phase. Before the implementation in the Eunomia code, the dominant processes have been highlighted by means of a global model and the results are presented hereafter. A verification of the extracted processes will follow and will be presented in section 2.2.5. 


\subsubsection{Plasimo results: new reaction paths in the presence of nitrogen}

Global modelling can provide deep insights into the plasma chemistry occurring in a rather complex environment. Considering the shape of $\mathrm{n}_{\mathrm{e}}$ and $\mathrm{T}_{\mathrm{e}}$ in a semi-detached plasma beam in linear machines, two different cases of study have been considered. For both cases, a $5 \% \mathrm{~N}_{2}$ content has been studied. In figure 2 a typical semi-detached Magnum-PSI $\mathrm{T}_{\mathrm{e}}$ and $\mathrm{n}_{\mathrm{e}}$ profiles are shown.

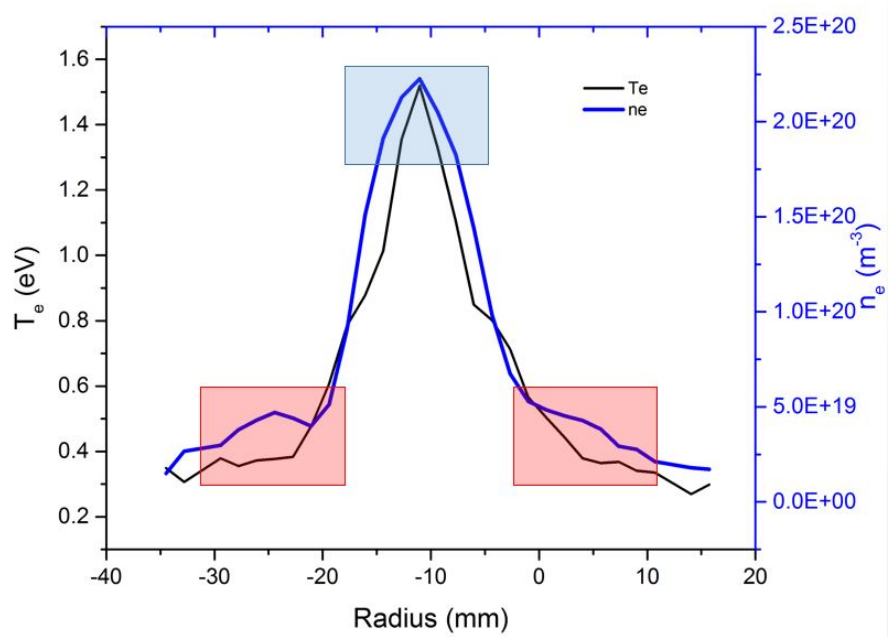

Figure 2. Electron temperature and density profiles of a 'semi-detached' Magnum-PSI plasma beam diagnosed by means of Thomson Scattering at $3 \mathrm{~cm}$ from the target. The two different cases of study are highlighted in blue (peak) and red (edges). The background pressure in the target chamber is set at 2Pa.

TS profiles are peaked in the centre and decrease towards the edge of the beam, with values from $\approx$ $1.5 \mathrm{eV}$ to $\approx 0.35 \mathrm{eV}$ for $\mathrm{T}_{\mathrm{e}}$ and from $\approx 2 * 10^{20} \mathrm{~m}^{-3}$ to $2.5^{*} 10^{19} \mathrm{~m}^{-3}$ for $\mathrm{n}_{\mathrm{e}}$. Clearly, such differences imply different plasma chemical processes to be dominant on a local scale.

\subsubsection{Centre of the plasma beam}

For the simulation of the centre of the plasma beam, the parameters calculated by the code are $T_{e}=$ $1.2 \mathrm{eV}$ and $\mathrm{n}_{\mathrm{e}}=2.65^{*} 10^{20} \mathrm{~m}^{-3}$. The most relevant processes highlighted in this section are reported in Figure 3. The initial densities are $1^{*} 10^{21} \mathrm{~m}^{-3}$ for molecular hydrogen and $5^{*} 10^{19} \mathrm{~m}^{-3}$ for $\mathrm{N}_{2}$. The input power density adopted to achieve parameters relevant for this study was set at $2500 \mathrm{~J} / \mathrm{m}^{3}$. The simulation time is set at $1.3 \mathrm{~ms}$.

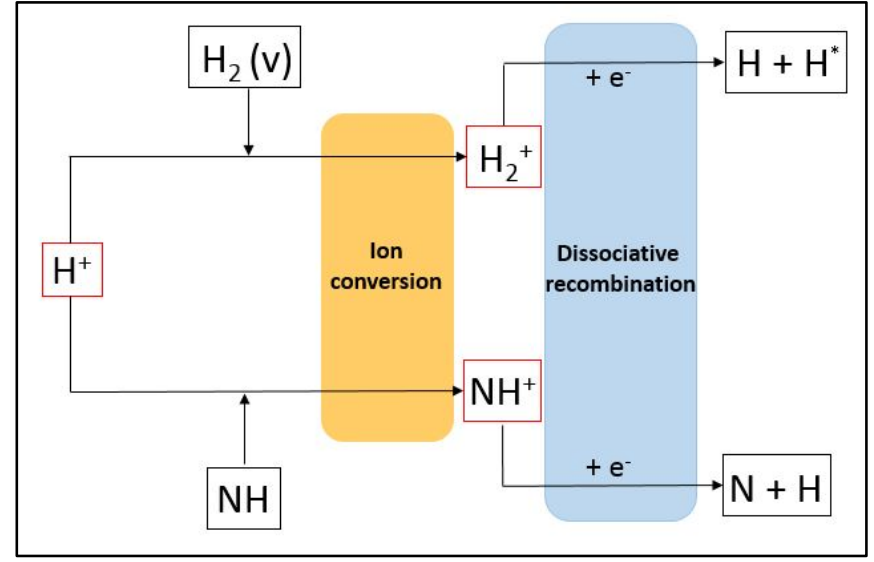

Figure 3. $\mathrm{H}^{+}$sink routes calculated by the code in the centre of the beam. The first branch, concerning $\mathrm{H}_{2}$ in vibrational excited state, corresponds to the well-established molecular activated recombination. The second one involves $\mathrm{NH}$ as electron donor in the ion conversion with $\mathrm{H}^{+}$and is followed by electron-ion recombination of $\mathrm{NH}^{+}$. This reactions path can be referred to as $N-M A R$. 
The principal sinks reactions for $\mathrm{H}^{+}$is ion conversion with molecular hydrogen in vibrational excited state and with $\mathrm{NH}$ (reactions 62 and 64) , leading $\mathrm{H}_{2}{ }^{+}$and $\mathrm{NH}^{+}$respectively. The first branch is the wellestablished hydrogenic MAR first step, while the second involves nitrogen monohydride and will be referred to as $\mathrm{N}-\mathrm{MAR}$. The main loss route of $\mathrm{H}^{+}$is indicated by the code to be reaction 62 with a relative contribution of $\approx 70 \%$. In this model one vibrational excited state of $\mathrm{H}_{2}$ i.e. $v=4$, is taken into account. $\mathrm{NH}$ molecule is produced via electron-impact direct dissociation of $\mathrm{NH}_{\mathrm{x}}$ species, dissociative recombination of $\mathrm{NH}_{\mathrm{x}}{ }^{+}$ions and by neutral-neutral atomic transfer (reactions 49 and 81).

About $85 \%$ of $\mathrm{H}_{2}{ }^{+}$is lost by dissociative recombination (reaction 19) and, to a minor extent by reacting with $\mathrm{N}$-species, namely $\approx 10 \%$ is consumed by proton transfer with $\mathrm{N}_{2}$ (reaction 66 ) and $\approx 5 \%$ by ion conversion with ammonia (reaction 65) gaining $\mathrm{N}_{2} \mathrm{H}^{+}$and $\mathrm{NH}_{3}{ }^{+}$respectively. As can be seen in figure 4 , the dominant $\mathrm{NH}^{+}$sink path is by dissociative recombination ( $\left.\approx 90 \%\right)$, gaining one atom of nitrogen and one of hydrogen (reaction 21) and for less than $10 \%$ by atom transfer with $\mathrm{N}$, producing $\mathrm{N}_{2}{ }^{+}$and $\mathrm{H}$ (reaction 83).

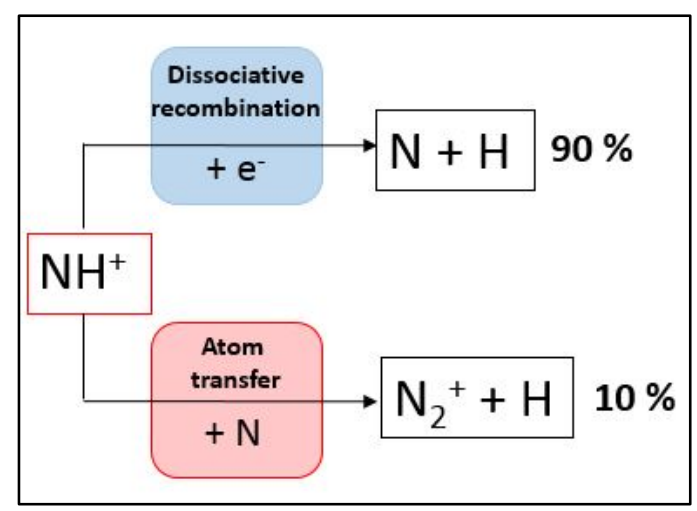

Figure 4. relative contribution of $\mathrm{NH}^{+}$sinks in the beam centre.

No significant amount of ammonia or its derivate ion $\mathrm{NH}_{4}{ }^{+}$is produced in the volume phase. The precursors of those species are rapidly consumed by dissociation and recombination processes. In a real divertor $\mathrm{NH}_{3}$ is produced by means of Eley-Rideal and Langmuir-Hinshelwood processes, both involvinga (cold) metal wall[52]. The molecule is then released in the volume phase. Althoughthis can occur in a detached-like plasma scenario in a linear device, no wall processes have been implemented in this simulation, given the purpose of studying the most important volume-phase plasma chemistry. Assuming an influx of $\mathrm{NH}_{3}$ from the target and/or from the reactor walls towards the plasma beam, ammonia undergoes ion conversion with $\mathrm{H}^{+}$(reaction 61 ) with a contribution of $42 \%$, dissociation by electron impact for $25 \%$ (indicated as the sum of relative contributions of reactions 38 and 39 ) and via $\mathrm{H}$ atom transfer (reaction 41) for the remaining 33\%. The product of reaction 61 i.e. $\mathrm{NH}_{3}{ }^{+}$is calculated to be entirely consumed by dissociative recombination i.e. reaction 26 and 27 , producing $\mathrm{H}_{2}+\mathrm{NH}$ and $\mathrm{NH}_{2}+\mathrm{H}$, respectively.

\subsubsection{Divertor-relevant $\mathrm{H}_{2} / \mathrm{N}_{2}$ plasma chemistry for different plasma parameters}

To investigate the relevant plasma chemistry occurring among a wider range of plasma scenarios, a parameter scan has been carried out i.e. electron densities from $6.8^{*} 10^{17} \mathrm{~m}^{-3}$ to $1.2^{*} 10^{19} \mathrm{~m}^{-3}$ have been studied. The electron temperature for these simulations has been kept at $2.5 \mathrm{eV}$, which is doubled compared to the Magnum-PSI detached-plasma relevant scenario discussed in section 2.2.2. In this sub-section, attention is paid to the density evolution of molecular ions, being the charged species populating this type of low-density plasmas [53]. Results are show in figure 5 and figure 6. 

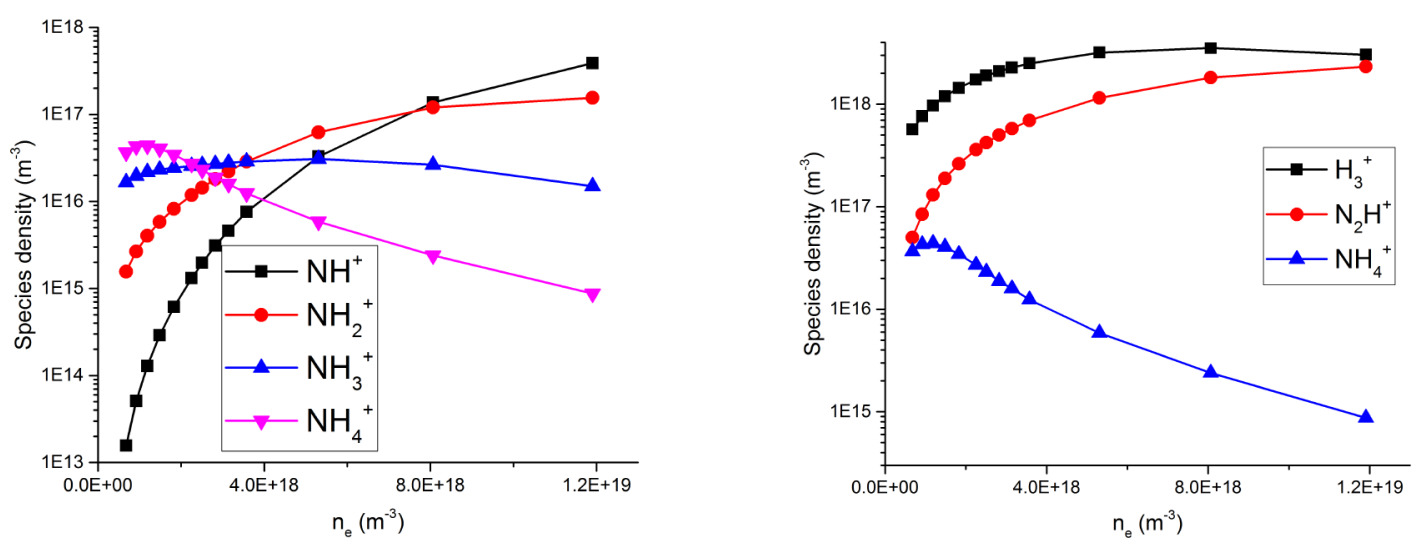

Figures 5 and 6. Density evolution of molecular ions in a $\mathrm{H}_{2} / \mathrm{N}_{2}$ plasma as a function of increasing electron density.

At high-density low-temperature plasma, $\mathrm{NH}_{x}{ }^{+}$species (with $0<\mathrm{x}<5$ ) are predominantly produced via ion conversion with $\mathrm{H}^{+}$and are efficiently depleted by means of dissociative recombination processes, as follows:
1) $\mathrm{H}^{+}+\mathrm{NH}_{x} \rightarrow \mathrm{NH}_{x}^{+}+\mathrm{H}$
Ion conversion
2) $\mathrm{NH}_{x}^{+}+e^{-} \rightarrow \mathrm{NH}_{x-1}+\mathrm{H}$
Dissociative recombination

At the densities evaluated in figure 5 and 6 , other processes become dominant. These are govemed by the presence of protonated molecules. In figure 6 one can observe that at $\mathrm{n}_{\mathrm{e}}=1.2^{*} 10^{19} \mathrm{~m}^{-3}$, the densities of $\mathrm{NH}_{\mathrm{x}}$ species follow inversely the amount of $\mathrm{H}$ atoms bound to $\mathrm{N}$. In such scenario, dissociative recombination is still important, and tends to de-populate first the highly hydrogenated molecularions. When moving towards lower electron densities i.e. $3^{*} 10^{18} \mathrm{~m}^{-3}$, a population inversion occurs, leading to an overturn where $\mathrm{NH}_{4}{ }^{+}$is the most present ion. This is due to the following atomic transfer reaction paths:
3) $\mathrm{NH}^{+}+\mathrm{H}_{2} \rightarrow \mathrm{NH}_{2}^{+}+\mathrm{H}$
Reaction 82
4) $\mathrm{NH}_{2}^{+}+\mathrm{H}_{2} \rightarrow \mathrm{NH}_{3}^{+}+\mathrm{H}$
Reaction 94
5) $\mathrm{NH}_{3}^{+}+\mathrm{H}_{2} \rightarrow \mathrm{NH}_{4}^{+}+\mathrm{H}$
Reaction 97

Moreover, $\mathrm{NH}_{4}{ }^{+}$is gained via a so-called proton transfer chain, which is initiated by $\mathrm{H}_{3}{ }^{+}$and molecular nitrogen. This path is characterised by the following reactions:
6) $\mathrm{H}_{3}^{+}+\mathrm{N}_{2} \rightarrow \mathrm{N}_{2} \mathrm{H}^{+}+\mathrm{H}_{2}$
Reaction 80
7) $\mathrm{N}_{2} \mathrm{H}^{+}+\mathrm{NH}_{3} \rightarrow \mathrm{NH}_{4}^{+}+\mathrm{N}_{2} \quad$ Reaction 98

This mechanism starts to occur at $\mathrm{n}_{\mathrm{e}}<4 * 10^{18} \mathrm{~m}^{-3}$ (figure 6), when the density of $\mathrm{H}_{3}{ }^{+}$and $\mathrm{N}_{2} \mathrm{H}^{+}$decrease steeply and $\mathrm{NH}_{4}{ }^{+}$increases. At density $\sim 8^{*} 10^{17} \mathrm{~m}^{-3}, \mathrm{~N}_{2} \mathrm{H}^{+}$and $\mathrm{NH}_{4}{ }^{+}$are almost equally populated. It is worth to underline here that reaction 80 is also a source for $\mathrm{H}_{2}$ which is a reactant participating in the above-mentioned atom transfer chain.

The effect of electron temperature on $\mathrm{H}_{2} / \mathrm{N}_{2}$ plasma chemistry with densities in the order of $10^{16} \mathrm{~m}^{-3}$ has been extensively studied in the last years [54], [55] given the importance it has in the field of plasma processing. For what concerns divertor-relevant electron densities i.e. $\mathrm{n}_{\mathrm{e}}>5^{*} 10^{19} \mathrm{~m}^{-3}$ with electron temperatures above $3 \mathrm{eV}$, electron-induced mechanisms are expected to play a major role. As can be seen in figure 7, with temperature above $~ 3 \mathrm{eV}$, the electron-impact ionization becomes dominant compared to the ion conversion - dissociative recombination mechanisms described in equations (1) and (2) in this paragraph. Therefore, the effect of enhanced recombination of $\mathrm{H}^{+}$given by N-MAR, becomes less important. 


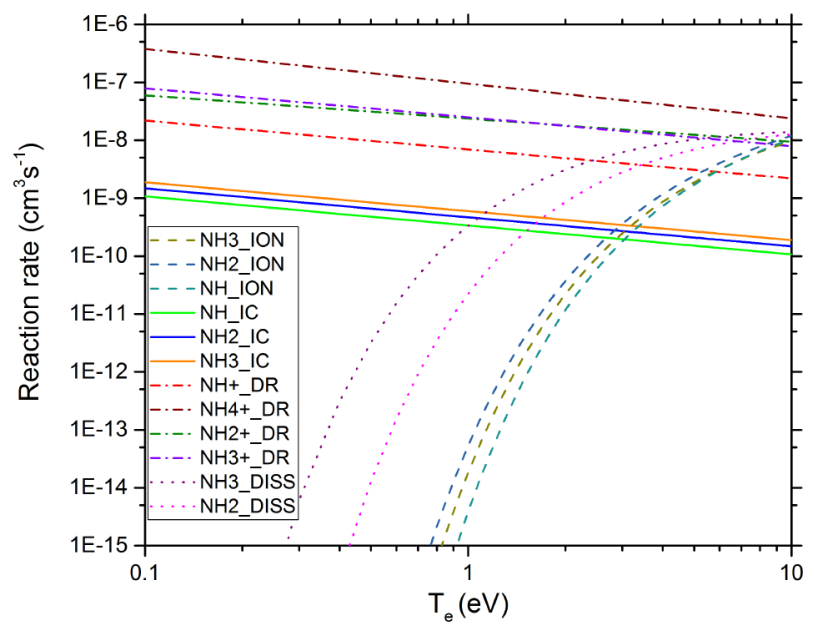

Figure 7. Reaction rates for $\mathrm{NH}_{\mathrm{x}}$ species occurring in divertor-relevant hydrogen plasma in the presence of nitrogen. Dotted lines are electron-impact dissociation (DISS), dash-dotted are dissociative recombination (DR), straight lines are ion conversion (IC) while dashed ones constitute direct ionization (ION).

\subsubsection{The role of molecular ion $\mathrm{H}_{3}^{+}$}

A parallel work has been carried out with the purpose of studying the presence of the protonated molecular hydrogen $\mathrm{H}_{3}{ }^{+}$in divertor-relevant plasmas. The same $\mathrm{H}_{2} / \mathrm{N}_{2}$ global model described in section 2.2.2 has been used, given that the plasma chemistry conditioning $\mathrm{H}_{3}{ }^{+}$is fully implemented.

The first successful studies on the production of such ion date back to the first half of the last century [56]. $\mathrm{H}_{3}{ }^{+}$is gained by means of a proton transfer reaction between molecular hydrogen and its ion (reaction 74): $\mathrm{H}_{2}^{+}+\mathrm{H}_{2} \rightarrow \mathrm{H}_{3}^{+}+\mathrm{H}$ with a rate constant of $\mathrm{k}=2 * 10^{-9} \mathrm{~cm}^{3} \mathrm{~s}^{-1}$ [43]. This process competes with another sink of $\mathrm{H}_{2}{ }^{+}$i.e. reaction 19: $\mathrm{H}_{2}^{+}+e^{-} \rightarrow \mathrm{H}+\mathrm{H}_{\mathrm{H}} \mathrm{H}_{3}{ }^{+}$is efficently consumed in low temperature plasmas $\left(\mathrm{T}_{\mathrm{e}}<3-4 \mathrm{eV}\right)$ by two dissociative recombination reactions, namely reactions 20 and 21 . The rate coefficients of these process as a function of $\mathrm{T}_{\mathrm{e}}$ are plotted in figure 8 . The density evolution of $\mathrm{H}_{3}{ }^{+}$over time is calculated by the code as:

$\frac{d\left[H_{3}^{+}\right]}{d t}=\left(k_{(74)} *\left[H_{2}^{+}\right] *\left[H_{2}\right]\right)_{\text {production }}-\left(k_{(20)} * n_{e} *\left[H_{3}^{+}\right]\right)_{\text {consumption }}-\left(k_{(21)} * n_{e} *\left[H_{3}^{+}\right]\right)_{\text {consumption }}$

It is dependent on the electron density. In the model, $\mathrm{T}_{\mathrm{e}}$ has been kept fixed at $\approx 1.5 \mathrm{eV}$ while the electron density has been changed by tuning the input power density provided into the system. The output of the simulations are reported in figure 9. 


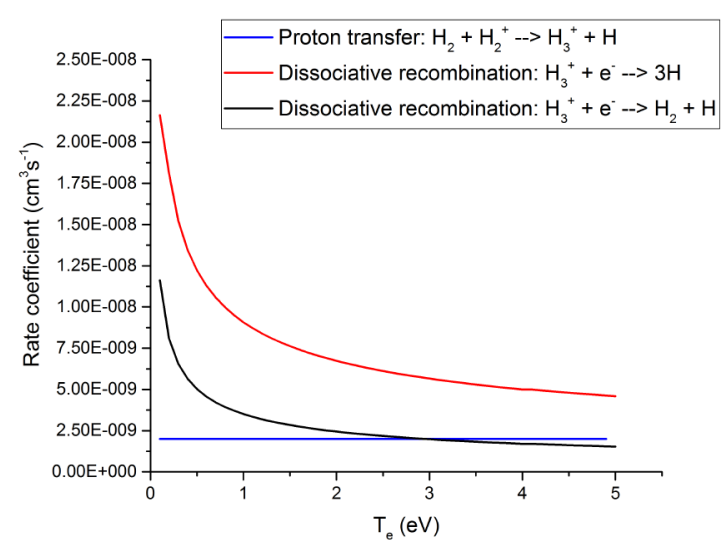

Figure 8. Rate coefficients as a function of $T_{e}$ for sources and sinks of $\mathrm{H}_{3}{ }^{+}$. Blue line corresponds to the source reaction 74 , while black and red are sink processes i.e. reactions 20 and 21 .

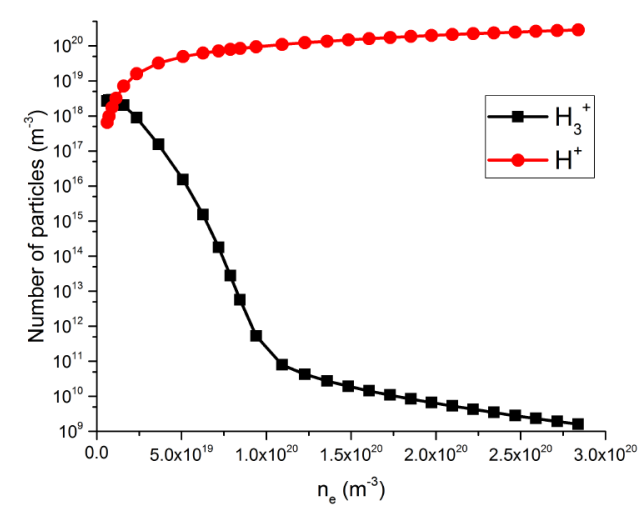

Figure 9. $\mathrm{H}^{+}$and $\mathrm{H}_{3}{ }^{+}$densities evolution as a function of $n_{e}$ calculated with the global model. Population inversion occurs at $\approx 7^{*} 10^{18} \mathrm{~m}^{-3}$. For divertor-relevant electron densities i.e. $>10^{20} \mathrm{~m}^{-3}$ the presence of $\mathrm{H}_{3}{ }^{+}$is negligible. Electron temperature was set at $1.5 \mathrm{eV}$.

The population inversion occurs at $\mathrm{n}_{\mathrm{e}} \approx 7^{*} 10^{18} \mathrm{~m}^{-3}$, which is about two orders of magnitude lower than the electron density characterizing the hydrogen plasma in new-generation linear machines as well as the one expected in ITER divertor i.e. $10^{20}-10^{21} \mathrm{~m}^{-3}$ [57]. Worth mentioning the typical "attached" $\mathrm{H}_{2}$ plasma in Magnum-PSI has $\mathrm{T}_{\mathrm{e}} \leq 5 \mathrm{eV}$, while for detached-like scenarios $\mathrm{T}_{\mathrm{e}}$ falls below $1.5 \mathrm{eV}$.

According to figure 8, for electron temperature between 1.5 and $5 \mathrm{eV}$, the production $\mathrm{H}_{3}{ }^{+}$is comparable with the destruction mechanisms. The limiting factor in divertor plasmas is the high electron density, leading to a very efficient recombination of $\mathrm{H}_{3}{ }^{+}$and its precursor $\mathrm{H}_{2}{ }^{+}$. Moreover in tokamaks, the electron temperature in the $\mathrm{SOL}$ is around $\approx 100 \mathrm{eV}$ in the upstream region [58]. At such temperatures, hydrogen is fully dissociated and ionized, making $\mathrm{H}^{+}$the only hydrogenic speciesflowing towards the divertor plate. Thus, we can deduce that the role $\mathrm{H}_{3}{ }^{+}$is negligible in Magnum-PSI and ITERrelevant divertor $\mathrm{H}_{2}$ plasma. The same conclusion has been obtained in [7].

\subsubsection{Periphery of the plasma beam}

In the edge of the plasma beam $\mathrm{T}_{\mathrm{e}}$ is about $0.8 \mathrm{eV}$ and $\mathrm{n}_{\mathrm{e}} \mathrm{i} \sim 5^{*} 10^{19} \mathrm{~m}^{-3}$. The most relevant plasma chemical mechanisms leading to the recombination of hydrogen ion and highlighted by the model for such scenario are shown in figure 10.

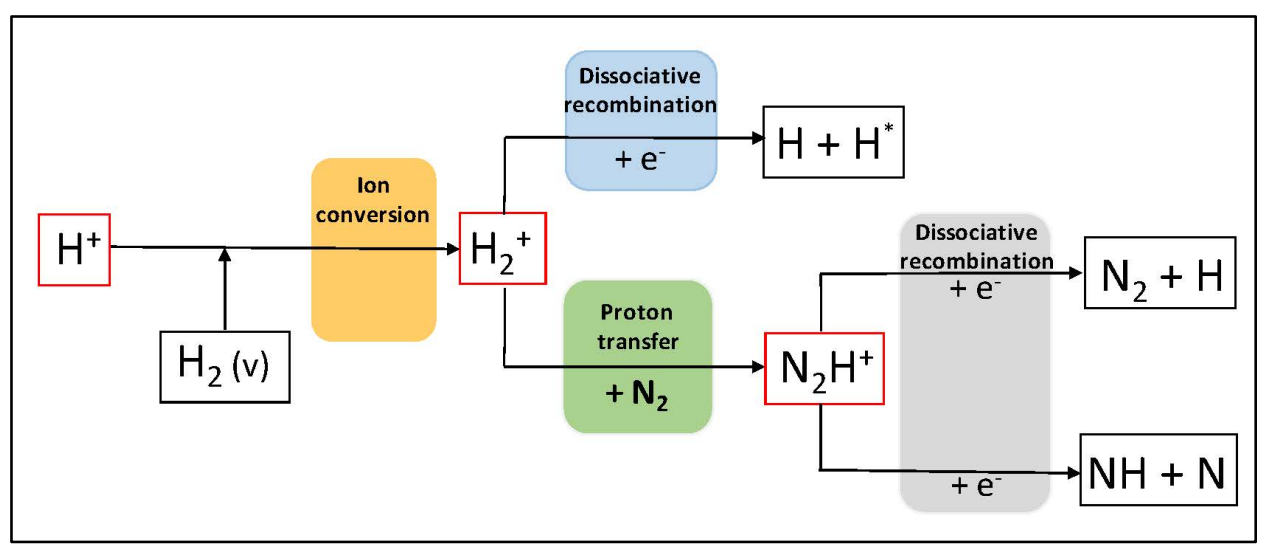


Figure 10. $\mathrm{H}^{+}$sink routes calculated by the code at the edges of the beam. The first step is the ion conversion with a hydrogen molecule in vibrational excited state, gaining $\mathrm{H}_{2}{ }^{+}$. This is followed by dissociative recombination (reaction 19) and proton transfer with $\mathrm{N}_{2}$ producing $\mathrm{N}_{2} \mathrm{H}^{+}$(reaction 66). Such species is then consumed via reactions 30 and 31 , producing $\mathrm{NH}$ and $\mathrm{N}_{2}$.

Differently from the centre of the beam, where $\mathrm{H}^{+}$undergoes two separate ion conversions, the principal sink route of $\mathrm{H}^{+}$in this case is almost entirely via ion conversion with $\mathrm{H}_{2}[\mathrm{v}]$, leading the production of $\mathrm{H}_{2}{ }^{+}$. This product is consumed by both dissociative recombination and proton transfer with $\mathrm{N}_{2}$, gaining two hydrogen atoms and $\mathrm{N}_{2} \mathrm{H}^{+}$respectively (reactions 19 and 66). The two sink processes of $\mathrm{H}_{2}{ }^{+}$in figure 10 have a relative contribution of $60 \%$ and $40 \%$ respectively. $\mathrm{N}_{2} \mathrm{H}^{+}$is then consumed by dissociative recombination (reactions 30,31 ) producing $\mathrm{NH}$ and $\mathrm{N}_{2}$. This additional branch involving $\mathrm{N}_{2}$ as proton acceptor will be referred to as another $\mathrm{N}-\mathrm{MAR}$ process. Differently from the conditions in the plasma centre, where the ion conversion is promptly followed by dissociative recombination, in the milder plasma edge conditions, a further molecular-induced step occurs indicating $\mathrm{N}_{2} \mathrm{H}^{+}$as ionic mediator.

$\mathrm{H}_{3}{ }^{+}$is found to be produced in a negligible amount in this case as well. This is different from what has been previously observed in PISCES-A[59], where $\mathrm{H}_{3}{ }^{+}$was detected in significant amount by mass spectrometry. Electron density in that study was between $10^{17}$ and $10^{18} \mathrm{~m}^{-3}[60]$. The density characterizing the edges of Magnum-PSI plasma and used in this study is above $10^{19} \mathrm{~m}^{-3}$, leading to an enhanced recombination frequency of the precursor $\mathrm{H}_{2}{ }^{+}$and efficient consumption mechanisms of $\mathrm{H}_{3}{ }^{+}$.

\subsubsection{Comparison between the full and the reduced global models}

To ultimately verify the reaction scheme derived from the fully extended Plasimo global model, a reduced version has been produced. The chemical species implemented in the new gl obal model and their steady-state densities are reported in table 3. All the most relevant hydrogenic species havebeen added, together with the nitrogen-related ones that were identified to play a major role in the considered plasma chemistry, as shown in the previous sections.

\begin{tabular}{|c|c|c|c|c|c|c|c|c|c|c|c|}
\hline & $\mathrm{n}_{\mathrm{e}}$ & $\mathrm{H}$ & $\mathrm{H}_{2}$ & $\mathrm{H}_{2} \mathrm{~V}$ & $\mathrm{H}^{+}$ & $\mathrm{H}_{2}{ }^{+}$ & $\mathrm{N}_{2}$ & $\mathrm{~N}$ & $\mathrm{NH}$ & $\mathrm{NH}^{+}$ & $\mathrm{N}_{2} \mathrm{H}^{+}$ \\
\hline EXT & $2.65 E 20$ & $1.74 E 21$ & $1.52 \mathrm{E} 16$ & $8.96 \mathrm{E} 14$ & $2.65 \mathrm{E} 20$ & $5.87 \mathrm{E} 14$ & $1.39 \mathrm{E} 19$ & $7.25 \mathrm{E} 19$ & $4.06 E 15$ & $1.29 \mathrm{E} 15$ & $2.15 \mathrm{E} 13$ \\
\hline RED & $2.61 \mathrm{E} 20$ & $1.73 \mathrm{E} 21$ & $1.62 \mathrm{E} 16$ & $8.2 \mathrm{E} 14$ & $2.61 \mathrm{E} 20$ & $6.32 \mathrm{E} 14$ & $1.03 \mathrm{E} 19$ & $8.18 \mathrm{E} 19$ & $1.3 \mathrm{E} 15$ & $4.11 \mathrm{E} 15$ & $2.11 \mathrm{E} 13$ \\
\hline
\end{tabular}

Table 3. Electron density together with the species included in the reduced model. The densities achieved in both the full and reduced models (for the centre-of-the-beam case of study) are reported.

The initial densities have been kept the same in both cases of study i.e. $1 * 10^{21} \mathrm{~m}^{-3}$ for $\mathrm{H}_{2}$ and $5^{*} 10^{19} \mathrm{~m}^{-}$ ${ }^{3}$ for $\mathrm{N}_{2}$. To achieve $T_{e}$ and $n_{e}$ as close as possible, the chosen input power density is $2300 \mathrm{~J} / \mathrm{m}^{3}$. This value is slightly lower than the one used in the full model simulation $\left(2500 \mathrm{~J} / \mathrm{m}^{3}\right)$ due to the lower amount of particle densities populating the reduced model. Given the longer period needed to reach the steady state in this run, the simulation time is set at $5 \mathrm{~ms}$. The achieved $\mathrm{T}_{\mathrm{e}}$ is $1.2 \mathrm{eV}$ in the full model and $1.16 \mathrm{eV}$ in the reduced one. The electron densities gained in the simulations are almost identical as well. This is very important in order to deal with the same plasma environment. The plasma chemical reactions adopted for the reduced model are listed in table 4 . The processes highlighted in figure 3 and figure 10, corresponding to the new N-MAR branches, have been included. Electron-induced ionization, vibrational excitation, dissociation and elastic collisions are also taken into account. For completeness, the most relevant neutral-neutral process has been implemented in the reduced version as well, namely reaction 49 . That is in fact the most important process in such environment that relates two neutral key-species i.e. molecular hydrogen and atomic nitrogen. The scope of this work is to maximally reduce the amount of species and plasma chemical reactions occurring in the volume of a detached-like scenario. In such way, the underlined mechanisms can be implemented in a 
more detailed spatially-resolved code. To compensate the absence of the main NH sources i.e. electron - impact dissociation of $\mathrm{NH}_{\mathrm{x}}$ species and dissociative recombination of their ionic derivatives, an extra source of $\mathrm{NH}$ has been added together with an identical sink of $\mathrm{N}$ and $\mathrm{H}\left(8^{*} 10^{20} \mathrm{~m}^{-3} \mathrm{~s}^{-1}\right)$; in this way, particle balance is conserved and the system is closed. The total amount of $\mathrm{NH}$ particles added in the simulation corresponds to $\approx 7 \%$ conversion of nitrogen to ammonia, which is in line with literature studies [61], [62], [63].

\begin{tabular}{|c|c|}
\hline Reaction & Type \\
\hline$H+e^{-} \rightarrow H^{+}+2 e^{-}$ & Ionization \\
\hline$H_{2}+e^{-} \rightarrow H_{2}^{+}+2 e^{-}$ & Ionization \\
\hline$N_{2}+e^{-} \rightarrow N+N+e^{-}$ & Dissociation \\
\hline$H_{2}+e^{-} \rightarrow H_{2} v+e^{-}$ & Vibrational excitation \\
\hline$H_{2} v+H^{+} \rightarrow H_{2}^{+}+H$ & Ion conversion \\
\hline$H_{2}^{+}+e^{-} \rightarrow H+H$ & Dissociative recombination \\
\hline$H_{2}+N \rightarrow N H+H$ & Atom transfer \\
\hline$N_{2}+H_{2}^{+} \rightarrow N_{2} H^{+}+N$ & Proton transfer \\
\hline$N_{2} H^{+}+e^{-} \rightarrow N_{2}+H$ & Dissociative recombination \\
\hline$N_{2} H^{+}+e^{-} \rightarrow N H+N$ & Dissociative recombination \\
\hline$N H+H^{+} \rightarrow N H^{+}+H$ & Ion conversion \\
\hline$N H^{+}+e^{-} \rightarrow N+H$ & Dissociative recombination \\
\hline$H+e^{-} \rightarrow H+e^{-}$ & Elastic \\
\hline$H_{2}+e^{-} \rightarrow H_{2}+e^{-}$ & Elastic \\
\hline$N+e^{-} \rightarrow N+e^{-}$ & Elastic \\
\hline$N_{2}+e^{-} \rightarrow N_{2}+e^{-}$ & Elastic \\
\hline
\end{tabular}

Table 4. List of the plasma chemical reactions implemented in the reduced model. The two N-MAR mechanisms, together with the most important hydrogen reactions and electron-induced processes, have been inserted in the model. Rate coefficients are the same as in the full version.

The achieved densities are shown in figure 11. The densities of the hydrogenic species are in very good agreement. This confirms the importance of the reactions producing $\mathrm{H}$, which are the ion conversion of $\mathrm{H}^{+}$with $\mathrm{H}_{2}(\mathrm{v}=4)$ and with $\mathrm{NH}$, and the dissociative recombination of $\mathrm{H}_{2}{ }^{+}$and $\mathrm{NH}^{+}$, gaining $2 \mathrm{H}$ and $\mathrm{N}$ $+\mathrm{H}$ respectively. $\mathrm{H}_{2}$ is consumed predominantly via electron-impact vibrational excitation and atom transfer with atomic nitrogen with a relative contribution of about $50 \%$ for each process.

$\mathrm{H}^{+}$in both cases is equal to the electron density. In these global models, quasi-neutrality is always maintained. $\mathrm{H}^{+}$is the main ionic species in the system and is consumed via ion conversions. Worth mentioning here that the so-called three-body recombination reaction i.e. $\mathrm{H}^{+}+e^{-}+$ $e^{-} \rightarrow H^{*}(n \geq 6)+e^{-}$, involving two electrons and $\mathrm{H}^{+}$, becomes efficient at temperatures below $0.7 \mathrm{eV}$ with densities above $1 * 10^{21} \mathrm{~m}^{-3}$, hence not relevant for the scenarioconsidered here. According to the models, $\mathrm{N}_{2}$ is depleted by means of electron-induced dissociation and proton transfer with $\mathrm{H}_{2}{ }^{+}$, the latter being highlighted as second branch of the $\mathrm{N}$-MAR processes. $\mathrm{N}$ main sources are via reaction 51 and reaction 23, which is the final step of the first N-MAR path (see figure 3).

The final densities of $\mathrm{NH}$ are in good agreement. The difference is due to the absence in the reduced version of the electronically excited species $\mathrm{N}_{2}\left(\mathrm{~A}^{3} \Sigma^{+}\right)$and its efficient atomic transfer with $\mathrm{H}$ (reaction 81), which acts as a source for $\mathrm{NH}$. Such discrepancy suggests the small importance of other NH sink mechanisms i.e. electron-impact dissociation (reaction 34 ) and atom transfer with $\mathrm{H}$ (reaction 51 ).

In both extended and reduced models, the main source of $\mathrm{NH}^{+}$is the ion conversion between $\mathrm{NH}$ and $\mathrm{H}^{+}$, as stated in section 2.2.2. The slight overestimation of this ion is due to either the absence of the following source collision (reaction 67) $\mathrm{H}_{2}^{+}+\mathrm{N} \rightarrow \mathrm{NH}^{+}+\mathrm{H}$ and the sink processes via proton transfer i.e. reaction 83 and 84 . Such reactions have not been included in the reduced model, 
considering that constitute less than $10 \%$ to the overall relative contribution of sources and sinks of $\mathrm{NH}^{+}$. Our aim is, in fact, to underline only the most important mechanisms leading to the conversion of atomic hydrogen ions to neutrals, addressing the volume processes introduced by nitrogencontaining species.

$\mathrm{N}_{2} \mathrm{H}^{+}$, pointed out to be an important ion mediator in section 2.2 .5 , is verified to be produced via proton transfer (reaction 66) and consumed by reaction 30 and 31.

To assure the validity of the reduced model among a wider range of plasma parameters, a comparison between the extended and the reduced model has been carried out for other two different scenarios i.e. beam-edge conditions with $\mathrm{T}_{\mathrm{e}}=0.8 \mathrm{eV}$ and $\mathrm{n}_{\mathrm{e}}=6^{*} 10^{19} \mathrm{~m}^{-3}$ and a high-density higher-temperature case with $\mathrm{n}_{\mathrm{e}}=3.4^{*} 10^{20} \mathrm{~m}^{-3}$ and $\mathrm{T}_{\mathrm{e}}=1.8 \mathrm{eV}$. Results are shown in figure 11 . The densities of the underlined relevant species are again in very good agreement. We hereby prove the validity of the reduced set of chemical equations for parameters $5^{*} 10^{19}<\mathrm{n}_{\mathrm{e}}<3.5^{*} 10^{20} \mathrm{~m}^{-3}$ and $0.8<\mathrm{T}_{\mathrm{e}}<2 \mathrm{eV}$. For scenarios with $n_{\mathrm{e}}<10^{19} \mathrm{~m}^{-3}$, a different reduced set of reactions would be needed, namely the processes reportedin section 2.2.3. In such plasma environment, molecular ions become the major ion species, being proton transfer the dominant ion-neutral inelastic mechanism. An implementation of those processes in a spatially-resolved code is beyond the scope of this work, which focuses on Magnum-PSI relevant plasma scenarios.
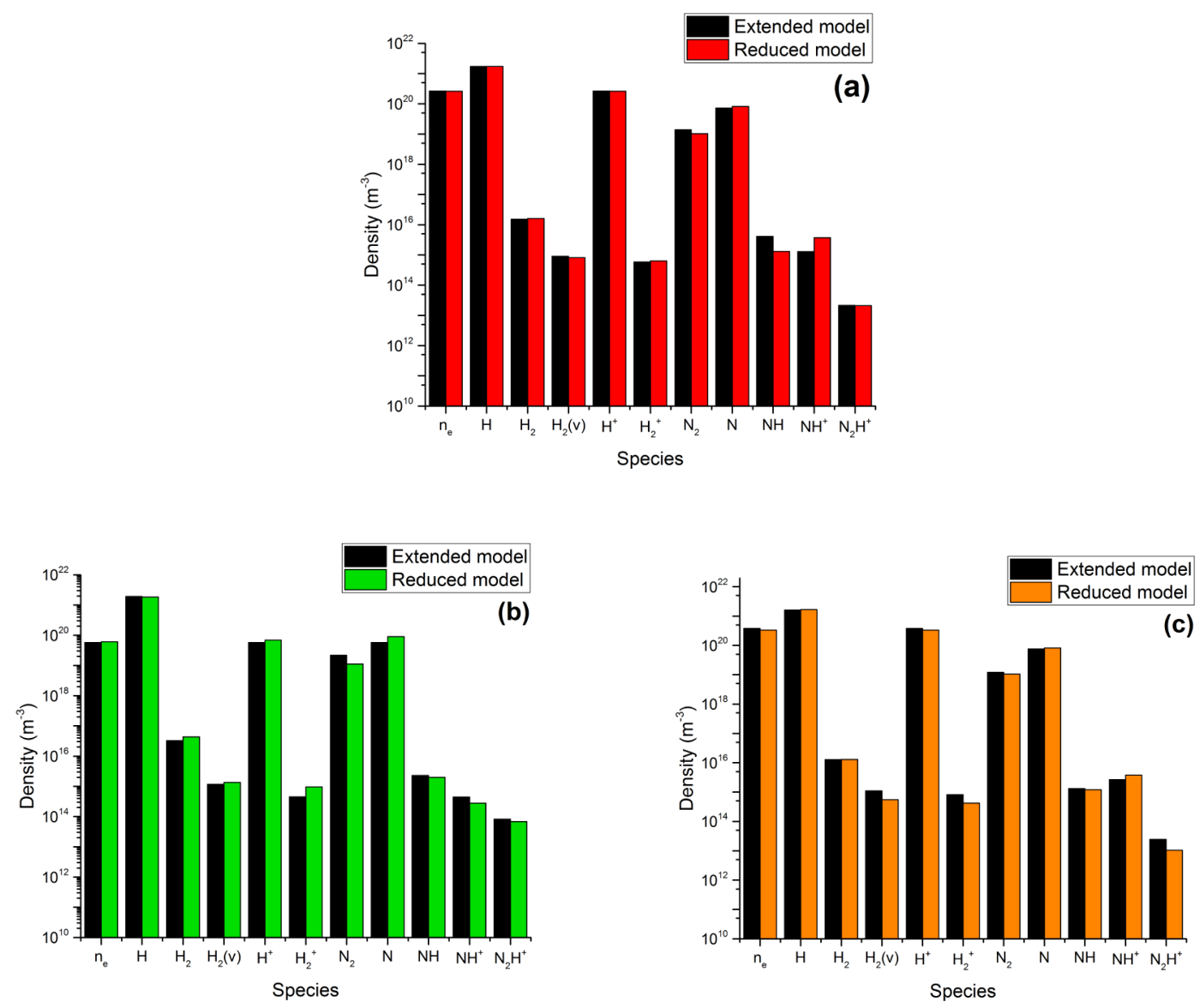

Figure 11. Species density comparison between the extended and the reduced model. (a) $T_{e}=1.2, n_{e}=2.6 E 20 m^{-3}$. (b) $T_{e}=$ $0.8, n_{e}=6 E 19 m^{-3}$. (c) $T_{e}=1.8, n_{e}=3.5 E 20 m^{-3}$. 
The work carried out in this section served to validate the derived set of reactions and species from the full model. The most effective relations, named N-MAR and stated in figure 3 and figure 10 have been confirmed by this exercise to be the most relevant. The delicate balance between the different species densities set by the chemical equations and validated here, has to be considered true only for the scenario considered i.e. divertor-relevant high-density low-temperature hydrogen plasma in the presence of nitrogen. These processes have been included in Eunomia and a description of the implementation will be given hereafter.

\section{Eunomia code}

Eunomia is a spatially resolved Monte-Carlo code created to simulate neutral particles in linear plasma machines, originally suited to model the neutral inventory in Pilot-PSI and Magnum-PSI. The code is conceptually similar to the well-established Monte Carlo code Eirene[64]. The code solves the equilibrium density, flow velocity and temperature of the ground state species and is based on the test-particle approximation method i.e. simulates test particles which represent many real neutral particles. In Eunomia charged particles are not simulated and plasma equations are not solved. The plasma background is given as an input and $T_{e}$ and $n_{e}$ have been taken from Thomson Scattering measurements in Magnum-PSI[65]. In the code, test particles never interact with each other; they undergo through test particle- background particle collisions as follows: a charged particle or a neutral particle is drawn from the maxwellian velocity distribution from the background to be collided with the test particle. Information about species densities and velocity distributions subsequent to each collision event are stored by the code over the simulation grid for every cycle. That constitutes the temporary neutral background, that will be substituted by the newly calculated one the next cycle. In Eunomia, such process is called scoring. In order to calculate sources and sinks for the neutral background, many test-particles are simulated. Each time a test particle visits a cell, the code stores its residence time as estimator of relative density. To determine the actual particle density, the number of real particles represented by a test-particle has to be given as input. The input determinesalso either the number of test particles or the maximum time to be modelled. Once a source is simulated, the number of test particles is known. The actual number of particles is then calculated by the code as:

$$
N_{r p}=\Gamma_{r p} \tau_{a}
$$

Where $\Gamma_{r p}$ is the influx of real particles into the system per second and $\tau_{a}$ is the averaged residence time. Although no direct effects on the plasma can be modelled with Eunomia in the stand-alone version, important insights on the behaviour of neutral atoms and molecules, such as their sources, sinks, spatial distribution and transport, can be studied. Further specifications on the code, such as calculation of velocity distributions and temperatures, can be found in [11].

\subsection{Eunomia grid and geometry}

Figures 12 and 13, taken from [11], show a schematic view of the linear plasma machine Pilot-PSI and the derived cylindrical symmetry adopted in Eunomia. In the code, the simulation is carried out in a 3dimensional environment and the results are provided in a 2-D grid averaged over the rotation axis, as can be seen in figure 13.

Figure 14 shows the triangular grid on which the cell averaging is done in order to define the neutral background. The rate coefficients of each process is calculated at the beginning of each cycle as a function of the local $\mathrm{T}_{\mathrm{e}}$ and $\mathrm{n}_{\mathrm{e}}$. 

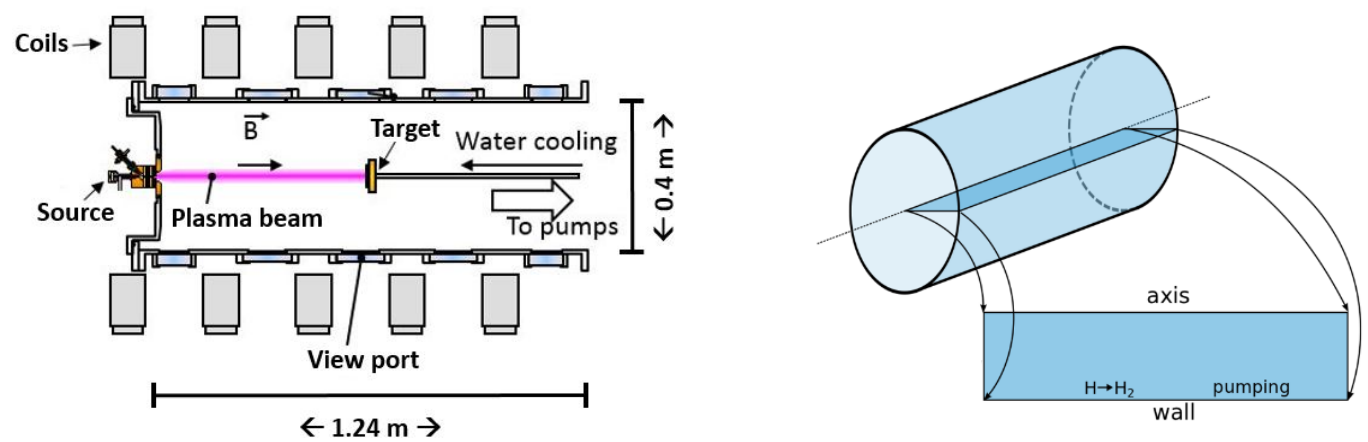

Figures 12, 13:. On the left: schematic view of linear machine Pilot-PSI; On the right: representation of the cylindrical symmetry used in Eunomia. Atomic hydrogen is assumed to react at the wall and is eventually re-emitted in the system in its molecular form.

As shown in figure 14, the cells have flexible areas and become larger moving away from the target. For each wall the test-particles can be either reflected or absorbed. For the axis of symmetry the testparticle will al ways undergo specular reflection. The walls can act as a recombining front of atomic hydrogen with the following mechanism: $H_{w}+H_{w} \rightarrow H_{2}$ bulk, where the product is released from the wall and enters the volume phase. $\mathrm{N}$-related species have been treated differently i.e. the particles impinging on a wall are thermalized and reflected with a cosine distribution. It is worth mentioning that gas-surface heterogeneous phenomena leading to the production of ammonia are beyond the aim of this study, which is entirely focused on volume processes.

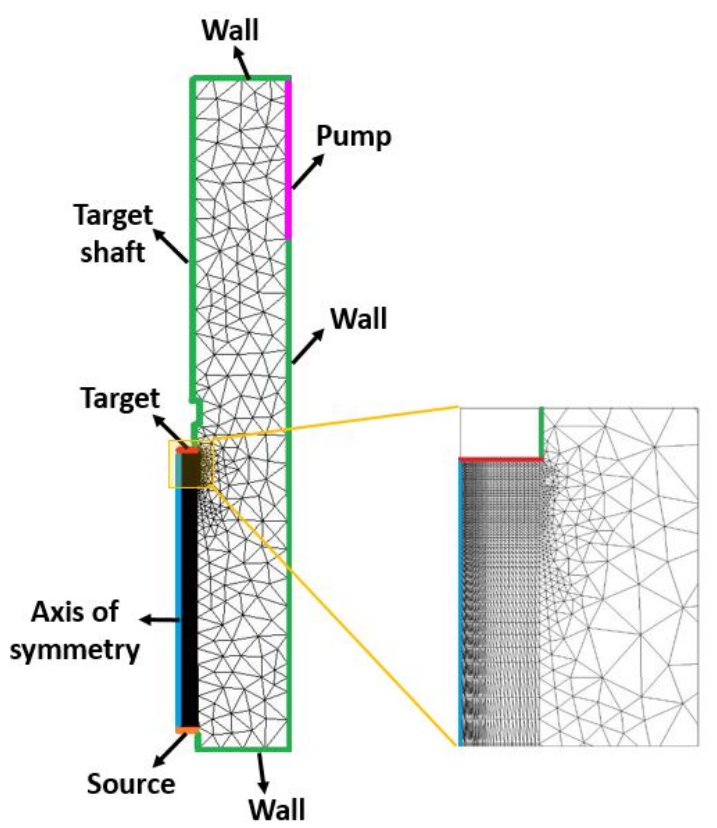

Figure 14. On the left, grid used for simulations. On the right a zoomed view of the target location.

The orange segment corresponds to the plasma source, the blue line is the axis of symmetry of the plasma beam and the red one is the target. Green lines are the walls of the vessel. The shaft of the target, indicated also in green, is treated by the code to act as a vessel wall. For the modelling of the pump (magenta segment in figure 14), the simulation of test-particle is stopped once it reaches that region. The grid depicted here and used in this work is a representation of the Pilot-PSI linear device[66]. 


\subsection{Implementation of the reduced model into Eunomia}

The hydrogen-related collisions used in the code are listed in table 5 . The cross sections for neutralneutral elastic collisions (reactions n. 1,2,3,9 and 10) are based on the Lennard-Jones potential [6] and the BGK approximation method is used[68]. The rates of such processes depend on the iteratively updated background of the ground-state species. The rates for inelastic collisions between neutrals and charged particles (reactions 5, 6, and 7) are imported from the AMJUEL[69] and HYDHEL[26] databases, which are the same used by Eirene code. For electron-induced processes (reactions 4, 6 and 8), the rates are calculated as a function of the local per-cell $T_{e}$ and $n_{e}$ at the beginning of each cycle.

\begin{tabular}{|c|c|c|}
\hline $\mathrm{N \#}$ & Reaction & Type \\
\hline 1 & $H+H \rightarrow H+H$ & Elastic \\
\hline 2 & $H+H_{2} \rightarrow H+H_{2}$ & Elastic \\
\hline 3 & $H_{2}+H_{2} \rightarrow H_{2}+H_{2}$ & Elastic \\
\hline 4 & $H+e^{-} \rightarrow H^{+}+2 e^{-}$ & Ionization \\
\hline 5 & $H^{+}+H \rightarrow H+H^{+}$ & Charge exchange \\
\hline 6 & $H_{2}+e^{-} \rightarrow H+H+e^{-}$ & Dissociation \\
\hline 7 & $H_{2}+H^{+} \rightarrow H+H_{2}^{+}$ & MAR \\
& $e^{-}+H_{2}^{+} \rightarrow H+H_{n=2}^{*}$ & \\
\hline 8 & $H_{2}+e^{-} \rightarrow H+H^{-}$ & MAR \\
& $H^{+}+H^{-} \rightarrow H+H_{n=3}^{*}$ & \\
\hline 9 & $H+H^{+} \rightarrow H+H^{+}$ & Elastic \\
\hline 10 & $H_{2}+H^{+} \rightarrow H_{2}+H^{+}$ & Elastic \\
\hline
\end{tabular}

Table 5. Hydrogenic reactions included in Eunomia.

The frequency of MAR processes (reactions 7 and 8 ) is governed by the first step i.e. ion conversion and dissociative attachment, respectively. The reaction intermediates $\mathrm{H}_{2}{ }^{+}$and $\mathrm{H}^{-}$are assumed to instantaneously recombine. The electronically excited states of atomic hydrogen produced in those processes are not simulated. The de-excitation probability of $\mathrm{H}^{*}(\mathrm{n}=2)$ gained in reaction 7 is calculated by the ratio between collisional excitation to $n=3$ and spontaneous decay, while for $\mathrm{H}^{*}(n=3)$ of reaction 8 , it is assumed to eventually ionize[70].

The additional nitrogen-included plasma chemistry actualized in the code corresponds to the one highlighted with global modelling and verified by the comparison with the full model, as described in section 2.2.5. In this implementation, neutral - neutral elastic collisions have been added for completeness and are listed in table 6 . Such collisions can affect the momentum of the test particles, hence they are important when deal ing with spatially-resolved transport codes. This is not the case for zero-dimensional-model, such as the global model platform provided by Plasimo. Data regarding potential energy curves and internuclear distances, needed for the BGK approximation, have been taken from [71], [72] and references therein.

\begin{tabular}{|c|c|}
\hline $\mathrm{NH}+\mathrm{H}_{2} \rightarrow \mathrm{NH}+\mathrm{H}_{2}$ & Elastic \\
\hline $\mathrm{NH}+\mathrm{H} \rightarrow \mathrm{NH}+\mathrm{H}$ & Elastic \\
\hline $\mathrm{NH}+\mathrm{N}_{2} \rightarrow \mathrm{NH}+\mathrm{N}_{2}$ & Elastic \\
\hline $\mathrm{NH}+\mathrm{N} \rightarrow \mathrm{NH}+\mathrm{N}$ & Elastic \\
\hline $\mathrm{H}_{2}+\mathrm{H}_{2} \rightarrow \mathrm{H}_{2}+\mathrm{H}_{2}$ & Elastic \\
\hline $\mathrm{H}_{2}+\mathrm{N}_{2} \rightarrow \mathrm{H}_{2}+\mathrm{N}_{2}$ & Elastic \\
\hline $\mathrm{N}_{2}+\mathrm{N}_{2} \rightarrow \mathrm{N}_{2}+\mathrm{N}_{2}$ & Elastic \\
\hline $\mathrm{H}+\mathrm{N} \rightarrow \mathrm{H}+\mathrm{N}$ & Elastic \\
\hline $\mathrm{H}+\mathrm{H} \rightarrow \mathrm{H}+\mathrm{H}$ & Elastic \\
\hline
\end{tabular}




\begin{tabular}{|c|l|}
\hline$N+N \rightarrow N+N$ & Elastic \\
\hline$N+N_{2} \rightarrow N+N_{2}$ & Elastic \\
\hline$H_{2}+N \rightarrow H_{2}+N$ & Elastic \\
\hline$N_{2}+H \rightarrow N_{2}+H$ & Elastic \\
\hline
\end{tabular}

Table 6. Neutral-neutral elastic collisions implemented in Eunomia.

$\mathrm{N}-\mathrm{MAR}$ mechanisms are treated in a similar way as the hydrogenic MARs i.e. reactions 7 and 8 in table 5: the products are assumed to recombine instantaneously, and the rate-determining step is the ion conversion. An update in the code has been made to include the atom transfer reaction i.e. $\mathrm{H}_{2}+$ $N \rightarrow N H+H$. This mechanism has been treated in a two-step process: firstly, this reaction acts as a source for $\mathrm{NH}$ and $\mathrm{H}$ i.e. these products are generated as new test particles based on the rate constant and the reactants background information. The velocities are drawn randomly from maxwellian distributions. Secondly, the particle balance is conserved by adding compensating collision process that terminates the reactant test particles i.e. $\mathrm{N}$ and $\mathrm{H}_{2}$, which follow the usual collision mechanics in the simulation. This collision also uses the same rate constant as the source reaction.

\subsection{Eunomia results}

Eunomia runs have been carried out by using the parameters that characterize a typical semi-detached hydrogen plasma in Magnum-PSI linear device i.e. $T_{e}$ peak $=1.5 \mathrm{eV}$ and $\mathrm{n}_{\mathrm{e}}=2.5^{*} 10^{20} \mathrm{~m}^{-3}$. In the code, both these parameters have a full-width half-maximum (FWHM) of $20 \mathrm{~mm}$ and are constant al ong the beam. In linear plasma machines detachment scenarios are achieved by means of gas puffing, causing an increased background neutral pressure. Neutrals play a major role in cooling down the plasma by means of electron - neutral and ion - neutral collisions, and by increasing the molecular-assisted recombination frequency[73]. Gas seeding has been modelled and the injection location has been set at the target. The key feature introduced by nitrogen seeding investigated in this paper is the enhanced frequency of the recombination mechanisms compared to a case where only $\mathrm{H}_{2}$ is puffed into the system. The most relevant $\mathrm{N}$-speciesacting as electron donor highlighted in this work is $\mathrm{NH}$. Precursor of such species is mostly ammonia. $\mathrm{NH}_{3}$ is almost entirely produced by means of surface processes. Although modelling of those wall-induced mechanisms is beyond the scope of this paper, which is strictly focused on volume processes, $\mathrm{NH}_{3}$ also acts as a source for $\mathrm{NH}$ through reactions 37 and 39 with $\mathrm{k}_{37}=1.5^{*} 10^{-9} \mathrm{~cm}^{3} \mathrm{~s}^{-1}$ and $\mathrm{k}_{39}=9.5^{*} 10^{-12} \mathrm{~cm}^{3} \mathrm{~s}^{-1}$. Ion conversion of ammonia (reaction 61) leading to $\mathrm{NH}_{3}{ }^{+}$is very efficient in this plasma environment, with $\mathrm{k}_{61}=1.33^{*} 10^{-9} \mathrm{~cm}^{3} \mathrm{~s}^{-1}$ for a gas temperature of $0.2 \mathrm{eV}$. Such temperature has been highlighted by previous studies [11] to be the temperature of neutrals in the plasma beam of Pilot-PSI and Magnum-PSI linear machines. In Eunomia, the gas temperature is provided as an output, and is calculated by the code to be $0.21 \mathrm{eV}$ in the simulations carried out and presented hereafter. Such high molecular temperature is considered by us to be due to the efficient ion-neutral elastic collision leading to momentum transfer, which acts as heating mechanism for heavy particles. Atomic and molecular nitrogen temperatures are in the same range i.e. between 0.15 and $0.24 \mathrm{eV}$. The temperature of atomic hydrogen given by the code goes up to $0.45 \mathrm{eV}$. We address this to be caused by the resonant charge exchange process i.e. $H^{+}+H \rightarrow H+$ $\mathrm{H}^{+}$, a well-known cooling mechanism for hydrogen ion (reaction 5 in table 5). $\mathrm{NH}_{3}{ }^{+}$undergoes dissociative recombination with a rate of $2.04^{*} 10^{-8} \mathrm{~cm}^{3} \mathrm{~s}^{-1}$ with $\mathrm{T}_{\mathrm{e}}=1.5 \mathrm{eV}$, leading $\mathrm{NH}$ and $2 \mathrm{H}$ (reaction 26). Another source of $\mathrm{NH}$ is the amino radical $\mathrm{NH}_{2}$. This species contributes to the production of $\mathrm{NH}$ via reactions 35 and 47 , namely electron-impact dissociation, with $k_{35}=2.57^{*} 10^{-10} \mathrm{~cm}^{3} \mathrm{~s}^{-1}$ and $\mathrm{k}_{47}=2.98^{*} 10^{-11} \mathrm{~cm}^{3} \mathrm{~s}^{-1}$ for $\mathrm{T}_{\mathrm{e}}=1.5 \mathrm{eV}$ and Tgas $=0.2 \mathrm{eV}$. Its ion derivative i.e. $\mathrm{NH}_{2}{ }^{+}$, which is produced via ion conversion (reaction 63) and proton transfer (reaction 82), contributes efficiently to the production of $\mathrm{NH}$ by means of dissociative recombination (reaction 24), with $\mathrm{k}_{24}=2.01 * 10^{-8} \mathrm{~cm}^{3} \mathrm{~s}^{-1}$. To take these processes into account in Eunomia runs, a source of $\mathrm{NH}$ from the target has been added, corresponding 
to $5 \%$ of the total nitrogen injected. The volume sources of $\mathrm{NH}$ included in the model are atom transfer and dissociative recombination of $\mathrm{N}_{2} \mathrm{H}^{+}$, both listed in table 4 .

In figure 15 the density distribution of $\mathrm{NH}$ calculated by Eunomia for a $5 \%$ nitrogen seeding case is shown. NH decreases moving away from the target al ong the plasma beam due to the effective N-MAR i.e. reaction 20 in table 4. Elastic collisions of $\mathrm{NH}$ with $\mathrm{N}_{2}$ and $\mathrm{H}_{2}$ may also play a role enhancing the perpendicular diffusion of the species in respect to the plasma beam. The density increases outside the beam, where the concentrations of $\mathrm{H}_{2}$ and $\mathrm{N}$ are high, leading an efficient atom transfer process.

In figure 16 the spatially-resolved collision frequency of the first N-MAR is shown. The test-particle collisional events are localized in the centre of the beam and in the vicinity of the target. This is in line with the density distribution of figure 16 , since in that region $\mathrm{NH}$ efficiently undergoes N-MAR. Such mechanism is addressed to further contribute to the conversion of incoming atomic hydrogen ions to neutrals, reducing the incoming flux towards the target and eventually making heat loads more tolerable for the material.
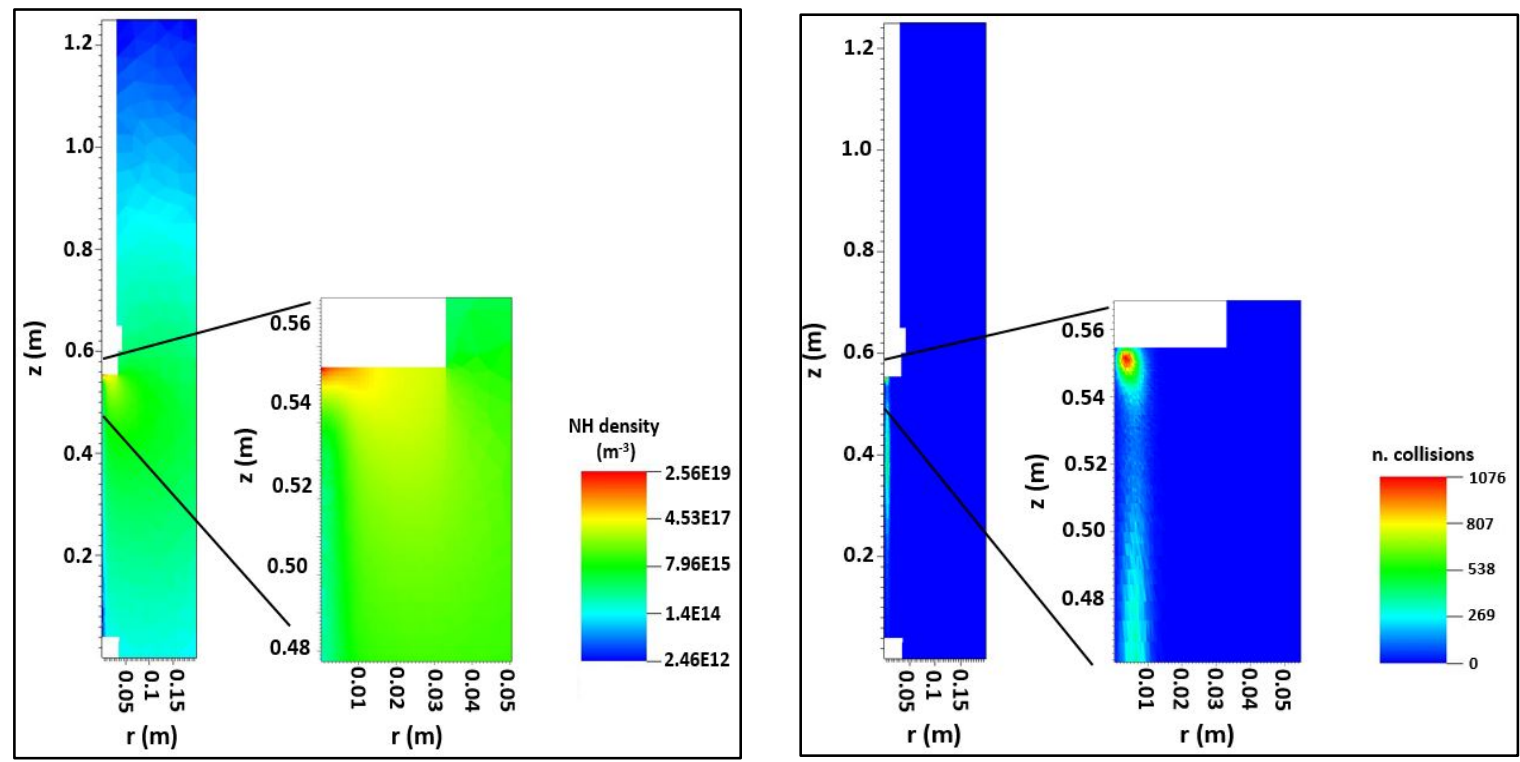

Figure 15. Two-dimensional density distribution of the key species NH calculated by Eunomia. The region close to the target is highlighted.

Figure 16. Collision frequency of the two-step $\left.\mathrm{N}-\mathrm{MAR}: 1) \mathrm{H}^{+}+\mathrm{NH} \rightarrow \mathrm{NH}^{+}+\mathrm{H} ; 2\right) \mathrm{NH}^{+}+e \rightarrow \mathrm{N}+\mathrm{H}$. The highest collisionality is located close to the centre of the plasma beam and in the vicinity of the target, the latter being also the seeding location. Values in colour bar represent the amount of collision per cycle per test-particle.

To quantify the influence of the N-MAR process on the overall recombination efficiency, three different cases of studies, characterized by different puffing scenarios, have been set up as follows:

$$
\frac{\left[N_{2}\right]}{\left[H_{2}\right]+\left[N_{2}\right]}=0,5,10 \%
$$

While keeping fixed the amount of molecules injected in the system from the target i.e. $2 \cdot 1 * 10^{20} \mathrm{~m}^{-3} \mathrm{~s}$ 1 , three different nitrogen contents have been examined. The aim is to compare the recombination efficiency by tracing the density of atomic hydrogen, which is eventually the end product of any recombination process in this specific plasma environment.

In figure 17 the $\mathrm{H}$-density radial profile taken at $3 \mathrm{~cm}$ in front of the target is shown. Interestingly, the $\mathrm{H}$ density in the plasma beam is higher in the $10 \%$ and $5 \%$ cases, compared to the only- $\mathrm{H}_{2}$ case. Values 
taken in the centre of the plasma beam are $8.75^{*} 10^{18}, 1.98 * 10^{19}$ and $2.74 * 10^{19} \mathrm{~m}^{-3}$ for 0,5 and $10 \% \mathrm{~N}_{2}$ content.

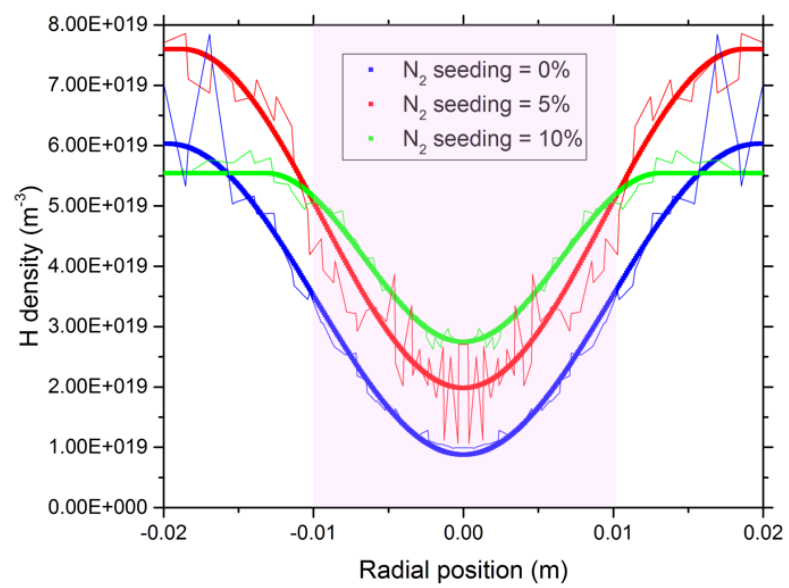

Figure 17. Density profiles of atomic hydrogen along radial coordinates. Simulation outputs in thin coloured line. Data have been fitted (thick coloured lines). The total amount of particles injected has been kept the same for all three cases, while changing the ratio of $\mathrm{N}_{2}$ from 0 to $10 \%$. The higher values among the nitrogen-seeded cases indicates an increase in the recombination. Pink background represent the region of the plasma beam in the simulations.

This indicates that the presence of $\mathrm{N}_{2}$ and, subsequently of $\mathrm{NH}$, contributes to further enhance recombination processes in the centre of the beam via N-MAR mechanisms.

The plasma beam in the simulations has a FWHM of $20 \mathrm{~mm}$. The region between radial position 0.01 and $0.02 \mathrm{~m}$ is characterised by strong gradient in terms of $T_{e}$ and $n_{e}$ i.e. from $1^{*} 10^{20}$ to $5^{*} 10^{16} \mathrm{~m}^{-3}$ and from 0.6 to $0.1 \mathrm{eV}$ for electron density and temperature respectively. Within the plasma beam width, the main source for atomic hydrogen is the static plasma itself i.e. $\mathrm{H}^{+} . \mathrm{H}$ is produced by means of recombination processes, specifically MAR and N-MAR. The seeding location in the simulations is set to be the target segment, hence, it has a wider surface compared to the beam, with a radius of $35 \mathrm{~mm}$. The density of $\mathrm{H}$ in the region between 10 and $20 \mathrm{~mm}$ radius i.e. outside the plasma beam, at $3 \mathrm{~cm}$ in front of the target is then barely influenced by plasma-neutrals inelastic collisions, whose study is the main scope of this work. The closeness to the target and the different $\mathrm{H}_{2} / \mathrm{N}_{2}$ seeding ratios led to a discrepancy in $\mathrm{H}$ density between the three cases of study. This is due to transport phenomena and elastic collisions. More detailed study on the transport of charged particles outward the beam will be carried out with the coupled codes B2.5-Eunomia.

Although no direct evidence on the contribution of $\mathrm{N}_{2} \mathrm{H}^{+}$increasing recombination frequency can be directly provided with this code, its importance is not to be considered only of a phenomenological nature. In fact, it acts as source for $\mathrm{NH}$, which has been proved to constitute the most important $\mathrm{N}$ related species in the conversion of ions to neutrals. Further studies on the reaction paths leading to $\mathrm{N}_{2} \mathrm{H}^{+}$, moreover, can contribute to the overall comprehension of the plasma chemical effects caused by the presence of nitrogen in the volume phase of a low-temperature hydrogen plasma.

\section{Summary and conclusions}

Volume reactions, such as molecular-assisted recombination, can contribute to reduce the incoming ion flux to the divertor plate. To understand the role of nitrogen in the plasma chemistry of a detached hydrogen plasma, numerical simulations are needed. A comprehensive global model has been set up by means of Plasimo code. Two newly-proposed molecular-assisted recombination processes, called $\mathrm{N}-\mathrm{MAR}$, have been highlighted. These reaction paths are: $\mathrm{NH}+\mathrm{H}^{+} \rightarrow \mathrm{NH}^{+}+\mathrm{H}$ followed by $\mathrm{NH}^{+}+e^{-} \rightarrow \mathrm{N}+\mathrm{H}$ in the centre of the beam (where parameters are very similar to the ones foreseen for ITER divertor) and $\mathrm{H}_{2}^{+}+\mathrm{N}_{2} \rightarrow \mathrm{N}_{2} \mathrm{H}^{+}+\mathrm{H}$ with the subsequent dissociative 
recombination of diazenilium i.e. $\mathrm{N}_{2} \mathrm{H}^{+}+e^{-} \rightarrow \mathrm{NH}+\mathrm{N}$ or $\mathrm{N}_{2}+\mathrm{H}$ in the periphery of the beam. A reduced global model including $\mathrm{N}-\mathrm{MARs}$ has been implemented and compared with the full model for three different $T_{e}$ and $n_{e}$ scenarios. Despite the lower number of species considered and the strong reduction of chemical reactions, the results match properly and the differences are all widely within the order of magnitude. This indicates the processes to be considered the dominant mechanisms occurring in the scenario examined. N-MARs, together with elastic collisions, electron impact dissociation and atomic transfer, have been implemented in Eunomia, a spatially-resolved Monte Carlo code suited for the transport of neutrals in linear machines. The test-particle collision frequency of the first N-MAR in Eunomia is showed to be centrally localized in the vicinity of the seeding location. The density of atomic hydrogen, which is the end product of recombination, has been monitored to compare the effectiveness of nitrogen-induced conversion of ions to neutrals. Results indicate that the presence of $\mathrm{N}_{2}$ affects the content of $\mathrm{H}$ by al most a factor 3 between only $\mathrm{H}_{2}$ and $10 \%$ nitrogen seeding cases of study. The newly-updated Eunomia code will be coupled with the fluid code B2.5. This will constitute an important numerical tool to study the effects of impurity seeding on detachment for both divertors and linear machines. The reduced plasma-chemical data set obtained in this work can be used and implemented also in other codes for the transport of neutrals in the divertor, such as EIRENE (embedded in SOLPS-ITER package)[74].

\section{Acknowledgments}

DIFFER is part of the Netherlands Organisation for Scientific Research (NWO). This work has been carried out within the framework of the EUROfusion Consortium and has received funding from both Euratom and NWO. The views and opinions expressed herein do not necessarily reflect those of the European Commission.

\section{Bibliography}

[1] M. Oberkofler et al., "First nitrogen-seeding experiments in JET with the ITER-like Wall," J. Nucl. Mater., vol. 438, no. SUPPL, pp. S258-S261, 2013.

[2] F. Reimold et al., "Divertor studies in nitrogen induced completely detached H-modes in full tungsten ASDEX Upgrade," Nucl. Fusion, vol. 55, no. 3, 2015.

[3] A. Kallenbach et al., "Plasma surface interactions in impurity seeded plasmas," J. Nucl. Mater., vol. 415, no. 1 SUPPL, pp. S19-S26, 2011.

[4] S. I. Krasheninnikov, "Physical mechanisms in divertors and their impact on the core," Czechoslov. J. Phys., vol. 48, no. SUPPL. 2, 1998.

[5] M. Wischmeier et al., "Current understanding of divertor detachment: Experiments and modelling," J. Nucl. Mater., vol. 390-391, no. 1, pp. 250-254, 2009.

[6] S. I. Krasheninnikov, A. S. Kukushkin, and A. A. Pshenov, "Divertor plasma detachment," Phys. Plasmas, vol. 23, no. 5, 2016.

[7] A. S. Kukushkin, S. I. Krasheninnikov, A. A. Pshenov, and D. Reiter, "Role of molecular effects in divertor plasma recombination," Nucl. Mater. Energy, vol. 12, pp. 984-988, 2017.

[8] N. Ohno, N. Ezumi, S. Takamura, S. Krasheninnikov, and a. Pigarov, "Experimental Evidence of Molecular Activated Recombination in Detached Recombining Plasmas," Phys. Rev. Lett., vol. 81, pp. 818-821, 1998.

[9] M. G. Rusbridge et al., "Observations of the interaction of a plasma stream with neutral gas: Evidence of plasma loss through molecular-activated recombination," Plasma Phys. Control. Fusion, vol. 42, no. 5 SUPPL. A, pp. 579-602, 2000. 
[10] "https://plasimo.phys.tue.nl/.".

[11] R. Wiggers, B2.5-Eunomia simulations of Pilot-PSI, PhD Thesis. Eindhoven University of Technology, 2012.

[12] J. Rapp et al., "Construction of the plasma-wall experiment Magnum-PSI," Fusion Eng. Des., vol. 85, no. 7-9, pp. 1455-1459, 2010.

[13] B. de Groot et al., "Extreme hydrogen plasma fluxes at Pilot-PSI enter the ITER divertor regime," Fusion Eng. Des., vol. 82, no. 15-24, pp. 1861-1865, 2007.

[14] C. Lee, D. B. Graves, M. a. Lieberman, and D. W. Hess, "Global Model of Plasma Chemistry in a High Density Oxygen Discharge," J. Electrochem. Soc., vol. 141, no. 6, pp. 1546-1555, 1994.

[15] P. M. J. Koelman, S. T. Mousavi, R. Perillo, W. A. A. D. Graef, D. B. Mihailova, and J. Van Dijk, "Studying complex chemistries using PLASIMO's global model," J. Phys. Conf. Ser., vol. 682, no. 1, 2016.

[16] B. S. Truscott, M. W. Kelly, K. J. Potter, M. Johnson, M. N. R. Ashfold, and Y. A. Mankelevich, "Microwave Plasma-Activated Chemical Vapor Deposition of Nitrogen-Doped Diamond. I. N2/H2 and NH3/H2 Plasmas," J. Phys. Chem. A, vol.119, no. 52, pp. 12962-12976, 2015.

[17] T. et al. Body, "A volume-averaged model of nitrogen-hydrogen plasma chemistry to investigate ammonia production in a plasma-surface-interaction device," Plasma Phys. Control. Fusion.

[18] D. McElroy, C. Walsh, A. J. Markwick, M. A. Cordiner, K. Smith, and T. J. Millar, "The UMIST database for astrochemistry 2012," no. 2013, 2012.

[19] R. C. Wieggers, P. W. C. Groen, H. J. de Blank, and W. J. Goedheer, "Simulation of the Neutral Inventory in the Piot-PSI Beam," Contrib. to Plasma Phys., vol. 52, no. 5-6, pp. 440-444, 2012.

[20] L. Marques, J. Jolly, and L. L. Alves, "Capacitively coupled radio-frequency hydrogen discharges: The role of kinetics," J. Appl. Phys., vol. 102, no. 6, 2007.

[21] Y. Wang, O. Zatsarinny, and K. Bartschat, "B -spline R-matrix-with-pseudostates calculations for electron-impact excitation and ionization of nitrogen," Phys. Rev. A-At. Mol. Opt. Phys., vol. 89, no. 6, pp. 1-12, 2014.

[22] Campbell. Let al., "Integral cross sections for electron impact excitation of electronic states of N 2," J. Phys. B At. Mol. Opt. Phys., vol. 34, pp. 1185-1199, 2001.

[23] W. L. Morgan, “Morgan database -- http://www.Ixcat.laplace.univ-tlse.fr." 2012.

[24] Y. Itikawa, "Cross sections for electron collisions with nitrogen molecules," J. Phys. Chem. Ref. Data, vol. 35, no. 1, pp. 31-53, 2006.

[25] J.-S. Yoon et al., "Cross Sections for Electron Collisions with Hydrogen Molecules," J. Phys. Chem. Ref. Data, vol. 37, no. 2, pp. 913-931, 2008.

[26] Janev, Ratko K., Langer, William D., Post, Douglas E., Jr., and Evans, Kenneth, Jr., Elementary processes in hydrogen-helium plasmas: Cross sections and reaction rate coefficients, vol. 4. 1987.

[27] V. Tarnovsky, H. Deutsch, and K. Becker, "Cross-sections for the electron impact ionization of NDx (x =1-3)," Int. J. Mass Spectrom. Ion Process., vol. 167-168, pp. 69-78, 1997.

[28] T. D. Märk, F. Egger, and M. Cheret, "Ionization of ammonia and deuterated ammonia by electron impact from threshold up to 180 eV," J. Chem. Phys., vol. 67, no. 8, pp. 3795-3802, 
1977.

[29] J. Brian, "The dissociative recombination of molecularions," Phys. Rep., vol. 186, no. 5, pp. 215-248, 1990.

[30] B. J. McCall et al., "Dissociative recombination of rotationally cold $H_{-}\{3\}^{\wedge}\{+\}$, , Phys. Rev. A, vol. 70, no. 5, p. 52716, 2004.

[31] J. R. Peterson et al., "Dissociative recombination and excitation of N2+: Cross sections and product branching ratios," J. Chem. Phys., vol. 108, no. 5, pp. 1978-1988, 1998.

[32] L. Vikor et al., "Branching fractions in the dissociative recombination of $\mathrm{NH} 4+$ and $\mathrm{NH} 2+$ molecularions," Astron. Astrophys., vol. 344, pp. 1027-1033, 1999.

[33] T. Amano, "The dissociative recombination rate coefficients of $\mathrm{H}_{3}^{+}, \mathrm{HN}^{+}{ }_{2}$, and $\mathrm{HCO}^{+}$, " J. Chem. Phys., vol. 92, no. 11, pp. 6492-6501, 1990.

[34] P. A. Lawson, D. Osborne, and N. G. Adams, "Effect of isotopic content on the rate constants for the dissociative electron-ion recombination of N2H+," Int. J. Mass Spectrom., vol. 304, no. 1, pp. 41-44, 2011.

[35] K. Van Laer, S. Tinck, V. Samara, J. F. De Marneffe, and A. Bogaerts, "Etching of low-k materials for microelectronics applications by means of a N2/H2 plasma: Modeling and experimental investigation," Plasma Sources Sci. Technol., vol. 22, no. 2, 2013.

[36] M. Yousfi and M. D. Benabdessadok, "Boltzmann equation analysis of electron-molecule collision cross sections in watervapor and ammonia," J. Appl. Phys., vol. 80, no. 12, pp. 66196630, 1996.

[37] M. Koshi et al., "Reactions of $\mathrm{N}\left({ }^{4} \mathrm{~S}\right)$ atoms with $\mathrm{NO}$ and $\mathrm{H}<\mathrm{inf}>2</ \mathrm{inf}>$," J. Chem. Phys., vol. 93, no. 12, 1990.

[38] N. Cohen, "The O + NH3 reaction: A review," Int. J. Chem. Kinet., vol. 19, no. 4, pp. 319-362, 1987.

[39] J. A. Miller and C. T. Bowman, "Mechanism and modeling of nitrogen chemistry in combustion," Progress in Energy and Combustion Science, vol. 15, no. 4. pp. 287-338, 1989.

[40] J. D. Mertens, A. Y. Chang, R. K. Hanson, and C. T. Bowman, "Reaction kinetics of NH in the shock tube pyrolysis of HNCO," Int. J. Chem. Kinet., vol. 21, no. 11, pp. 1049-1067, 1989.

[41] W. G. Mallard, F. Westley, J. T. Herron, R. F. Hampson, and D. H. Frizzel, “NIST Chemical Kinetics Database:Version 5.0," no. December, 1993.

[42] D. F. Davidson, K. Kohse-Hoinghaus, A. Y. Chang, and R. K. Hanson, "A pyrolysis mechanism for ammonia," Int. J. Chem. Kinet., vol. 22, no. 5, pp. 513-535, 1990.

[43] V. G. Anicich, "Evaluated Bimolecular Ion-Molecule Gas Phase Kinetics of Positive lons for Use in Modeling Planetary Atmospheres, Cometary Comae, and Interstellar Clouds," J. Phys. Chem. Ref. Data, vol. 22, no. 6, pp. 1469-1569, 1993.

[44] S. S. Prasad and J. Huntress, W. T., "A model for gas phase chemistry in interstellar clouds. IThe basic model, library of chemical reactions, and chemistry among C, N, and O compounds," Astrophys. J. Suppl. Ser., vol. 43, p. 1, 1980.

[45] R. A. Arakoni, A. N. Bhoj, and M. J. Kushner, "H2generation in Ar/NH3 microdischarges,"J. Phys. D. Appl. Phys., vol. 40, no. 8, pp. 2476-2490, 2007.

[46] D. Smith, P. Spanel, and C. A. Mayhew, "A selected ion-flow tube study of the reactions of O+, 
$\mathrm{H}+$ and $\mathrm{HeH}]+$ with several molecular gases at $300 \mathrm{~K}, "$ Int. J. Mass Spectrom. Ion Process., vol. 117, no. C, pp. 457-473, 1992.

[47] C. H. Kruger, "Nonequilibrium effects in thermal plasma chemistry," Plasma Chem. Plasma Process., vol. 9, no. 4, pp. 435-443, 1989.

[48] M. C. Zammit, J. S. Savage, D. V. Fursa, and I. Bray, "Complete Solution of Electronic Excitation and Ionization in Electron-Hydrogen Molecule Scattering," Phys. Rev. Lett., vol. 116, no. 23, 2016.

[49] B. Gordiets, C. M. Ferreira, M. J. Pinheiro, and A. Ricard, "Self-consistent kinetic model of lowpressure N2-H2 flowing discharges: I. Volume processes," Plasma Sources Sci. Technol., vol. 7, no. 3, pp. 363-378, 1998.

[50] K. Sugiyama, K. Akazawa, M. Oshima, H. Miura, T. Matsuda, and O. Nomura, "Ammonia synthesis by means of plasma over MgO catalyst," Plasma Chem. Plasma Process., vol. 6, no. 2, pp. 179-193, 1986.

[51] J. H. Van Helden et al., "Detailed study of the plasma-activated catalytic generation of ammonia in N2-H2 plasmas," J. Appl. Phys., vol. 101, no. 4, 2007.

[52] E. Carrasco, M. Jiménez-Redondo, I. Tanarro, and V. J. Herrero, "Neutral and ion chemistry in low pressure dc plasmas of $\mathrm{H} 2 / \mathrm{N} 2$ mixtures: routes for the efficient production of $\mathrm{NH} 3$ and NH4+," Phys. Chem. Chem. Phys., vol. 13, no. 43, p. 19561, 2011.

[53] E. Carrasco, I. Tanarro, V. J. Herrero, and J. Cernicharo, "Proton transfer chains in cold plasmas of $\mathrm{H}_{2}$ with small amounts of $\mathrm{N}_{2}$. The prevalence of $\mathrm{NH}_{4}{ }^{+}$, " Phys. Chem. Chem. Phys., vol. 15, no. 5, pp. 1699-1706, 2013.

[54] A. De Castro, D. Alegre, and F. L. Tabarés, "Ammonia formation in $\mathrm{N}<$ inf $>2</$ inf $>/ \mathrm{H}<$ inf $>2</$ inf $>$ plasmas on ITER-relevant plasma facing materials: Surface temperature and $\mathrm{N}<\mathrm{inf}>2</$ inf $>$ plasma content effects," J. Nucl. Mater., vol. 463, pp. 676679, 2015.

[55] M. Sode, W. Jacob, T. Schwarz-Selinger, and H. Kersten, "Measurement and modeling of neutral, radical, and ion densities in H2-N2-Arplasmas," J. Appl. Phys., vol. 117, no. 8, 2015.

[56] T. R. Hogness, "T H E IONIZATION OF HYDROGEN BY ELECTRON IMPACT AS INTERPRETED BY POSITIVE RAYANALYSIS," Univ. California, Dep. Chem., vol. 398, no. April, 1925.

[57] C. Watts et al., "Electron density measurements in the ITER fusion plasma," Nucl. Instruments Methods Phys. Res. Sect. A Accel. Spectrometers, Detect. Assoc. Equip., vol. 720, pp. 7-10, 2013.

[58] P. Stangeby, "The Plasma Boundary of Magnetic Fusion Devices," Inst. Phys. Publ., 2000.

[59] N. Ohno, "Plasma detachment in linear devices," Plasma Phys. Control. Fusion, vol. 59, no. 3, 2017.

[60] E. M. Hollmann, G. Antar, R. P. Doerner, and S. C. Luckhardt, "Omegatron mass spectrometer for analysis of ion concentrations in hydrogenic plasmas," Rev. Sci. Instrum., vol. 72, no. 1 II, pp. 623-626, 2001.

[61] V. Rohde, D. Neuwirth, M. Oberkofler, and U. Team, "Nitrogen bal ance and ammonia formation during nitrogen seeded discharges at ASDEX Upgrade," no. D, pp. 2-5, 2012.

[62] D. Neuwirth, V. Rohde, and T. Schwarz-Selinger, "Formation of ammonia during nitrogenseeded discharges at ASDEX Upgrade," Plasma Phys. Control. Fusion, vol. 54, no. 8, 2012. 
[63] J. H. Van Helden et al., "Detailed study of the plasma-activated catalytic generation of ammonia in N2-H2 plasmas," J. Appl. Phys., vol. 101, no. 4, pp. 0-12, 2007.

[64] D. Reiter, M. Baelmans, and P. Börner, "The eirene and B2-eirene codes," Fusion Sci. Technol., vol.47, no. 2, pp. 172-186, 2005.

[65] G. J. Van Rooij et al., "Thomson scattering at Pilot-PSI and Magnum-PSI," Plasma Phys. Control. Fusion, vol. 51, no. 12, 2009.

[66] G. J. Van Rooij et al., "Extreme hydrogen plasma densities achieved in a linear plasma generator," Appl. Phys. Lett., vol. 90, no. 12, 2007.

[67] J. Perrin, O. Leroy, and M. C. Bordage, "Cross-Sections, Rate Constants and Transport Coefficients in Silane Plasma Chemistry," Contrib. to Plasma Phys., vol. 36, no. 1, pp. 3-49, 1996.

[68] P. L. Bhatnagar, E. P. Gross, and M. Krook, "A model for collision processes in gases. I. Small amplitude processes in charged and neutral one-component systems," Phys. Rev., vol. 94, no. 3, pp. 511-525, 1954.

[69] D. Reiter, “The data file AMJUEL : Additional Atomicand Molecular Data for EIRENE FZ, Forschungszentrum J ulich GmbHFRG Version : April 26, 2011 Available via E-mail from d.reiter@fz-juelich.de,"pp.1-393, 2011.

[70] J. A. M. van der Mullen, "Excitation equilibria in plasmas; a classification," Physics Reports, vol. 191, no. 2-3. pp. 109-220, 1990.

[71] S. Srivastava and N. Sathyamurthy, "Ab Initio Potential Energy Curves for the Ground and Low Lying Excited States of $\mathrm{NH}$ - and the Effect of 2 Sigma(+/-) States on A-Doubling of the Ground State X-2 pi,"J. Phys. Chem. A, vol. 117, no. 36, pp. 8623-8631, 2013.

[72] M. Freindorf, Y. Shao, T. R. Furlani, and J. Kong, "Lennard-Jones parameters for the combined QM/MM method using the B3LYP/6-31+G*/AMBER potential," J. Comput. Chem., vol. 26, no. 12, pp. 1270-1278, 2005.

[73] S. Kado, H. Kobayashi, T. Oishi, and S. Tanaka, "Experimental investigations on hydrocarbonenhanced MAR processes in low temperature plasma in divertor simulator MAP-II," J. Nucl. Mater., vol. 313-316, no. SUPPL., pp. 754-758, 2003.

[74] S. Wiesen et al., "The new SOLPS-ITER code package," J. Nucl. Mater., vol.463, pp. 480-484, 2015. 